\title{
تفعيل التشارك المعرفي بين أعضاء هيئة التدريس لتحقيق الميزة التنافسية بالجامعات المصرية المة التية
}

* إيناس عبدالله أحمد عبدالعال

أ.م.د / هالة أمين مغاوري ***

أ.د / سوزان تحمه المهُي**

(المستخلص : (1)

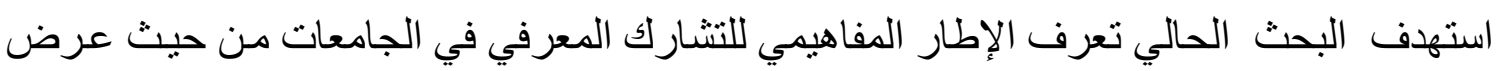

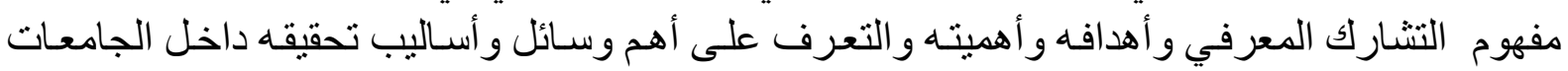

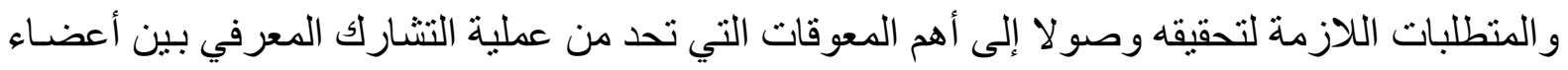

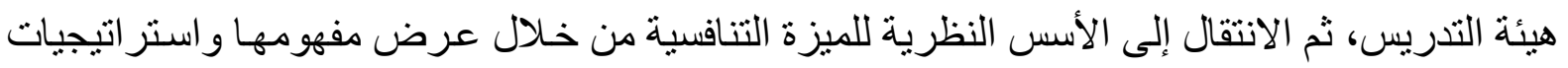

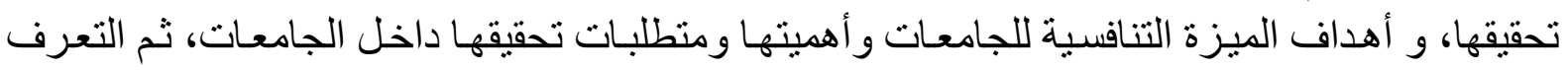

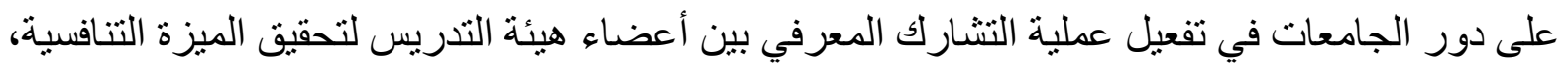

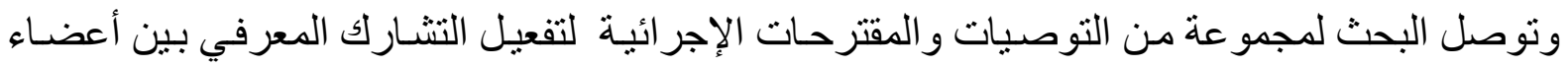

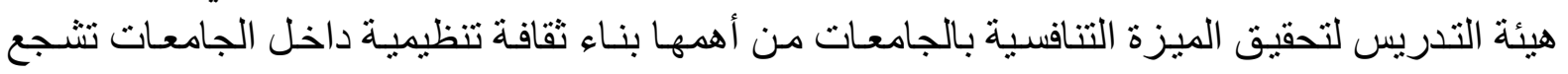

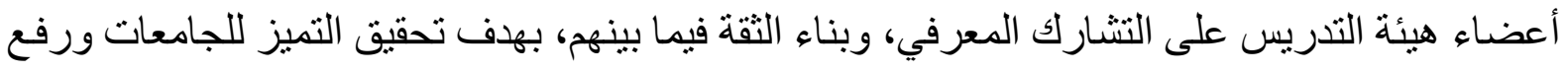

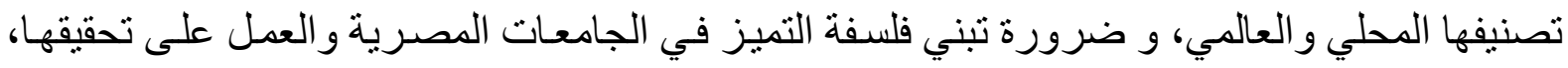

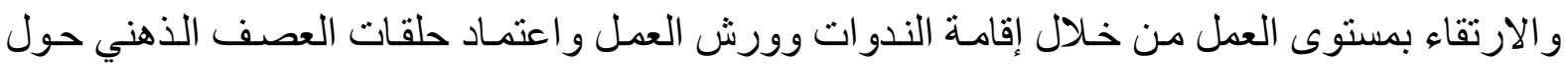

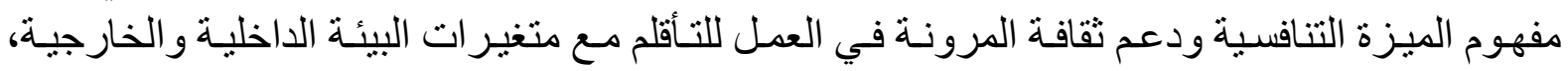
و استخدم البحث المنهج الوصفي لملائمنه لطبيعة البحث.

الكلمات المفتاحية: التشارك المعرفي، الميزة التنافسية، الجامعات المصرية، أعضاء هيئة التدريس لئس

Enas.ahmed@women.asu.edu.eg * المعيدة بقسم أصول التربية ـ كلية البنات- جامعة عين شمس - مصر ** أستاذ أصول التربية ـ كلية البنات - جامعة عين شمس - مصر Suzan-elmahdy@hotmail.com *** أستاذ مساعد أصول التربية ـ كلية البنات - جامعة عين شمس - مصر halamaghawry@hotmail.com 


\section{مقدمة}

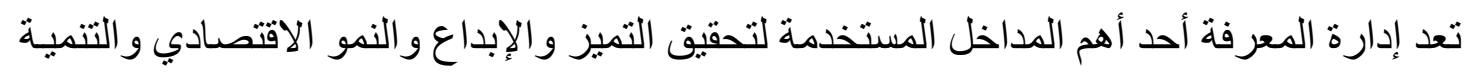

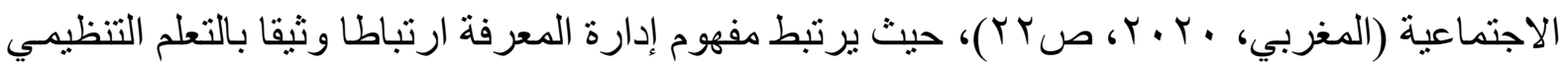

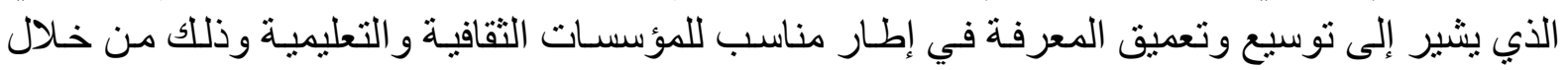

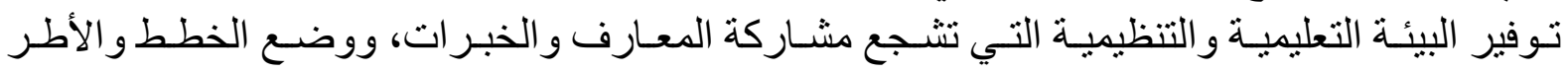

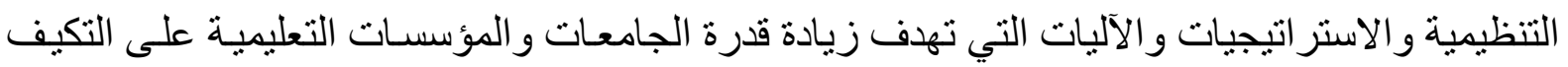

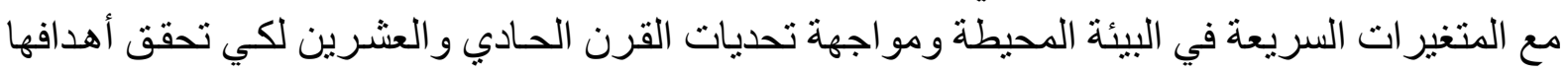

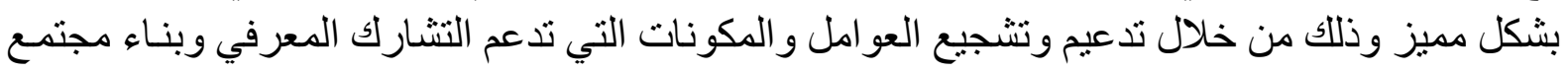

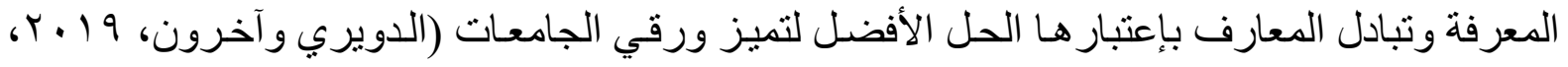

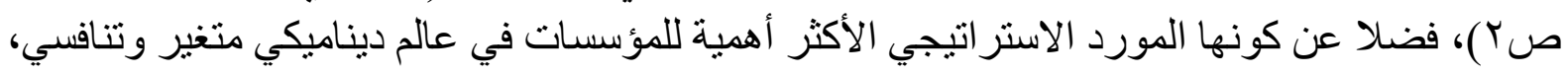

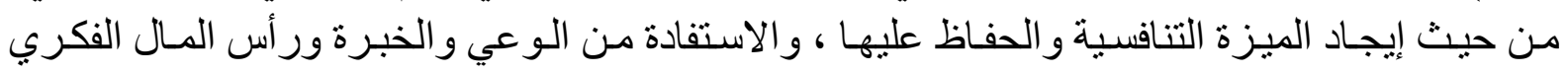

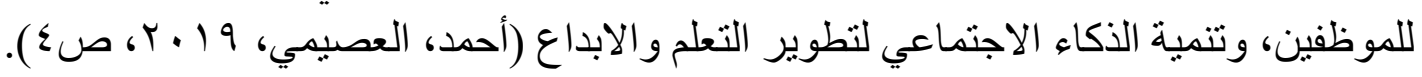

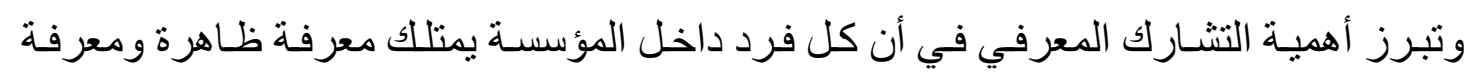

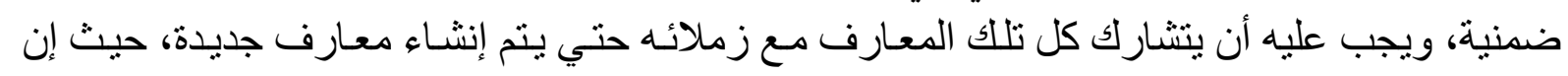

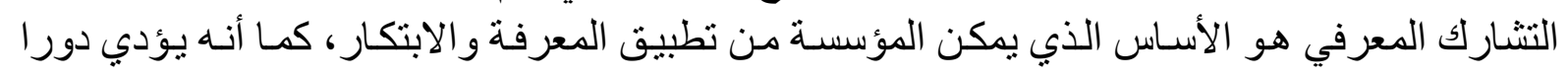
مهما في إدارة المعرفة (Zeng , 2018, p.58).

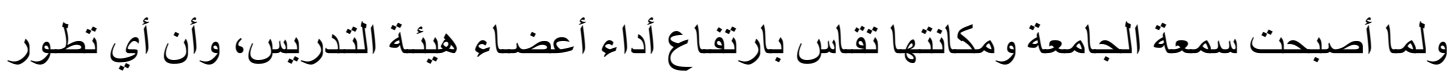

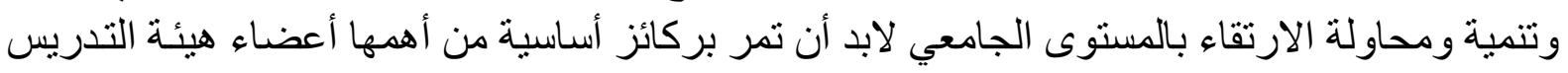

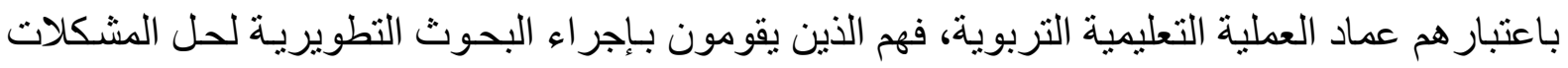

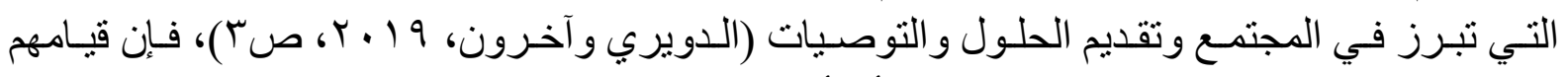

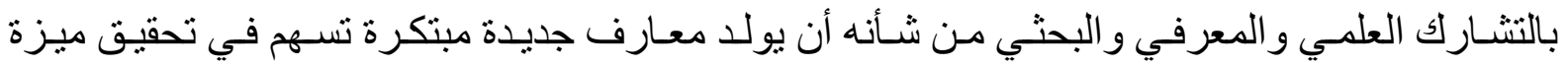

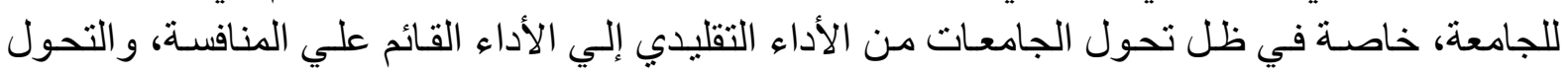

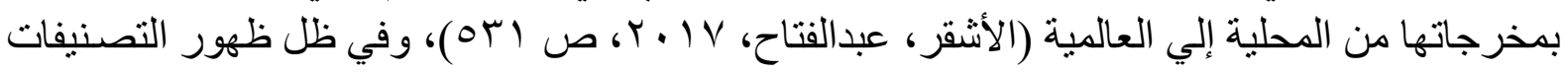

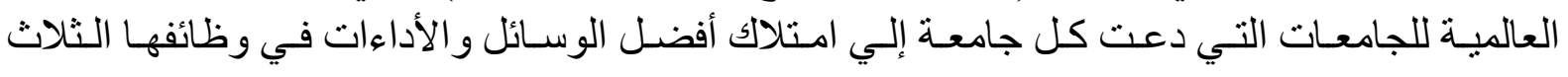

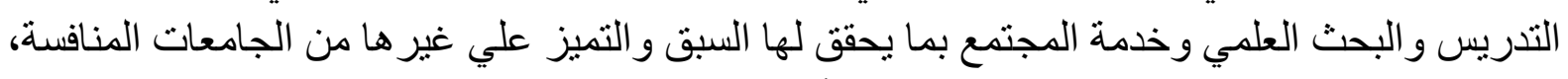

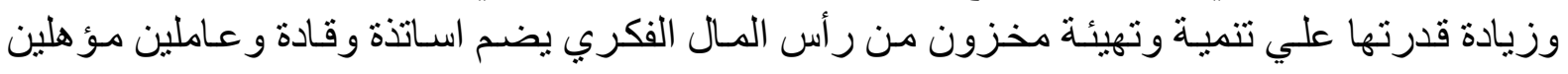

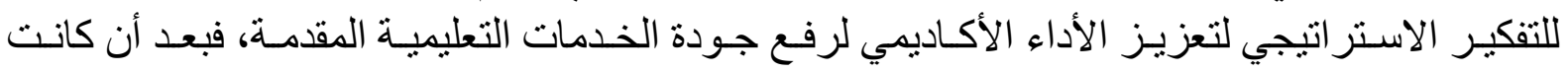

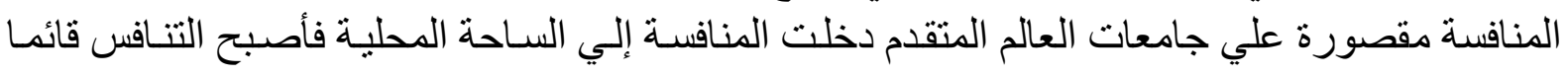

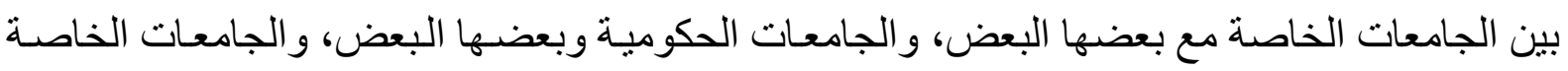

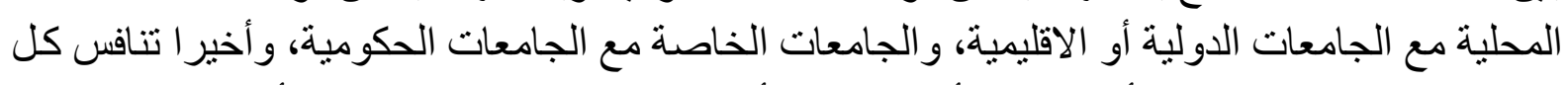

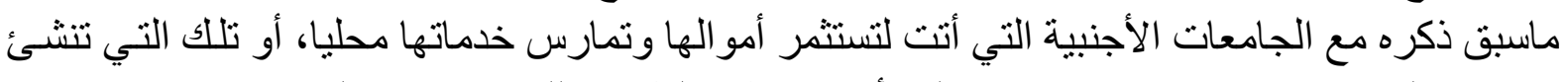

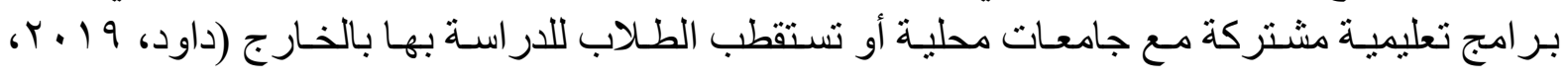
ص(7). 


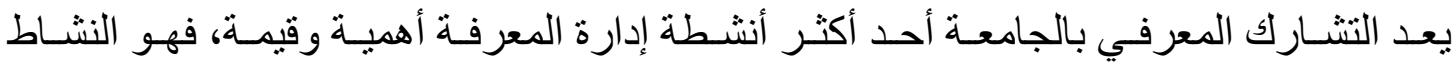

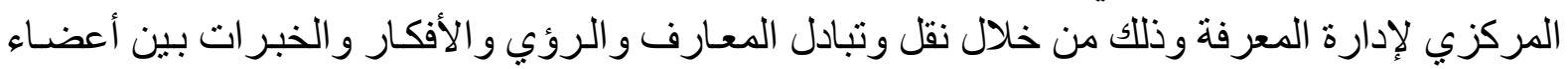

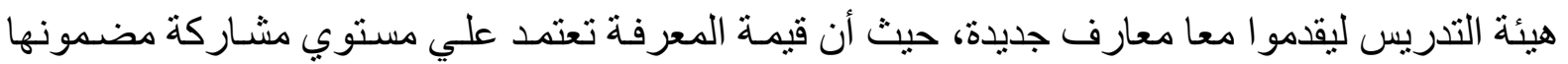

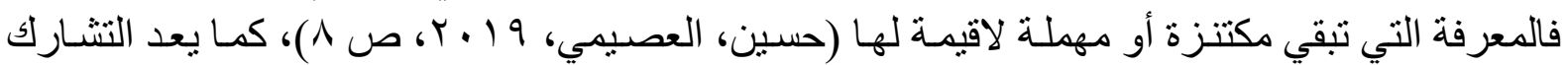

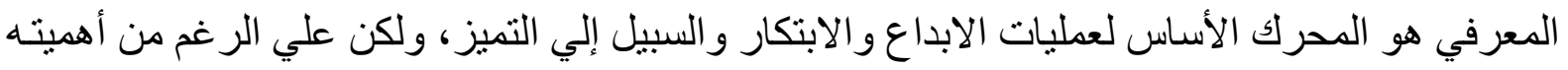

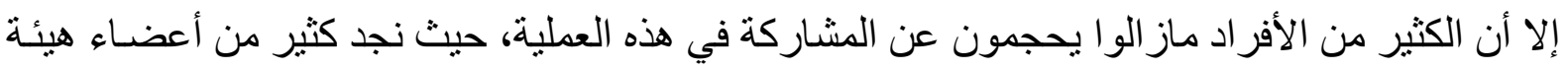

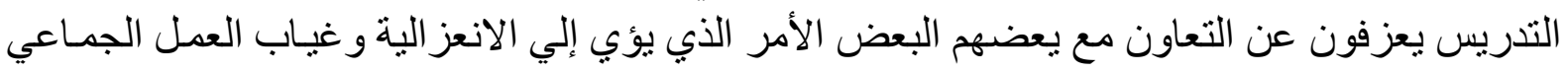

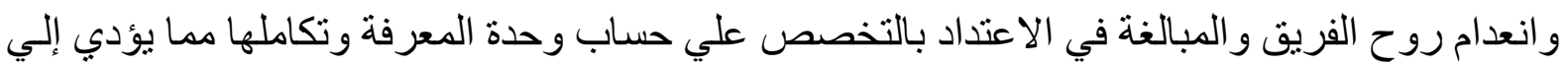

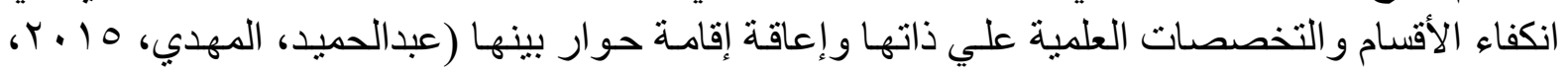

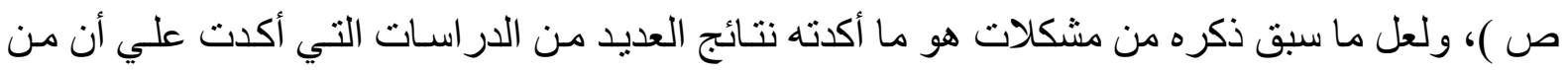

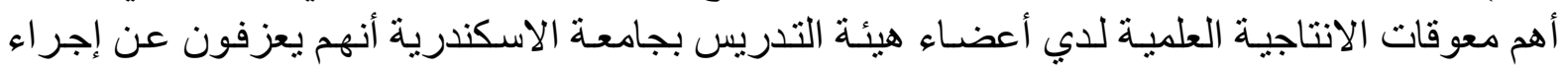

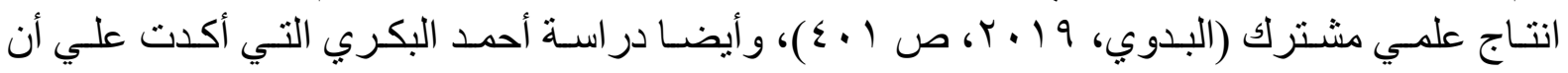

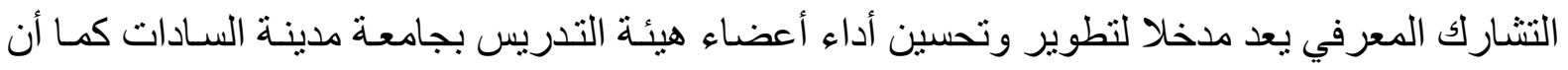

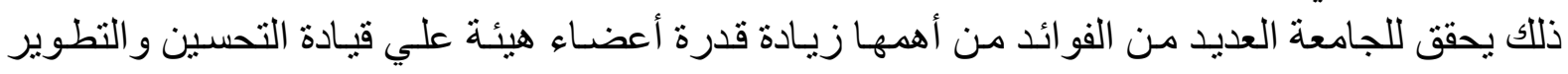

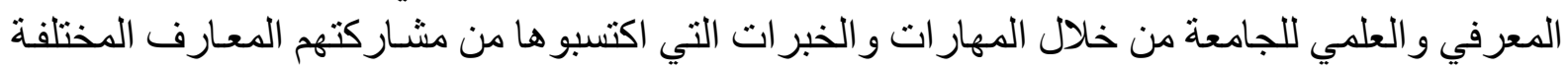

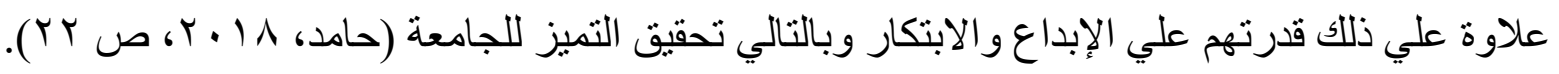

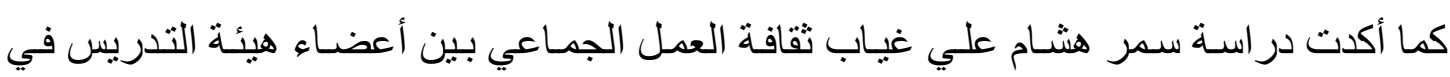

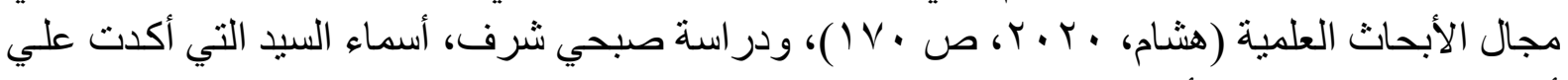

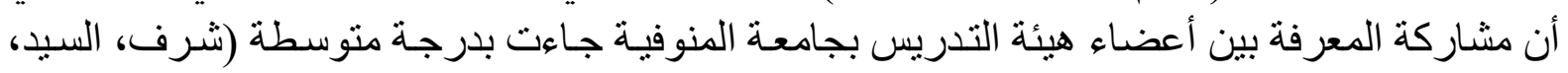

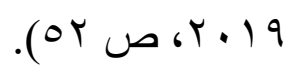

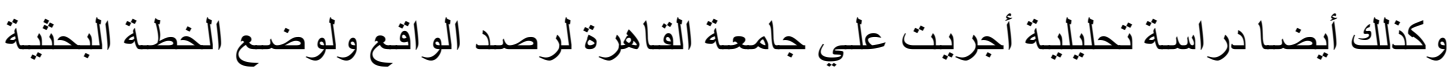

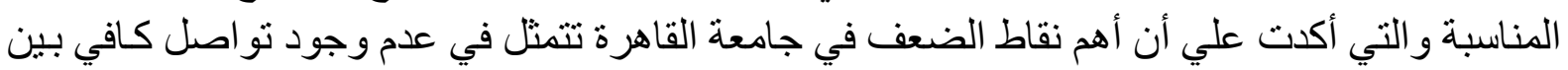

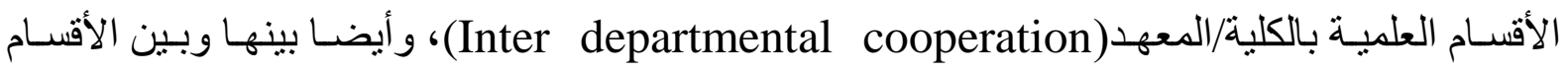

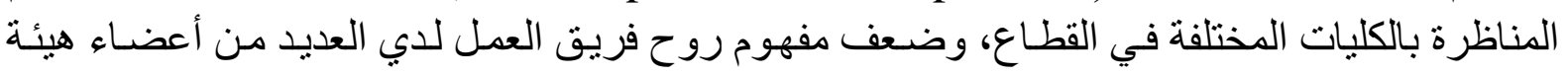

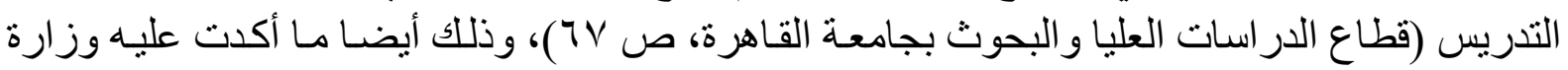

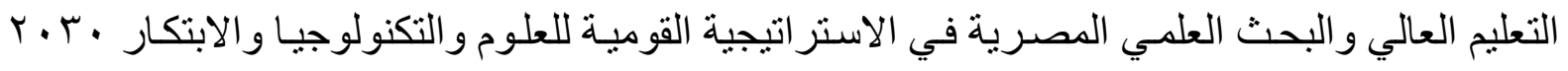

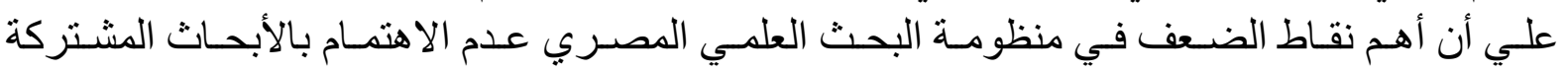

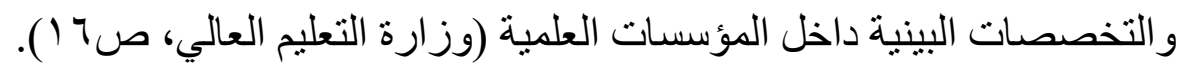

\section{وفي ضوء ما سبق يمكن طرح الأسئلة الأتية:}

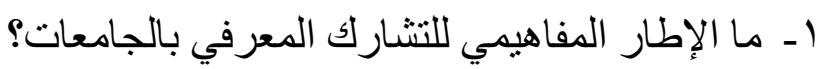

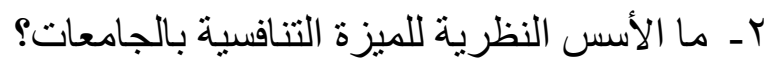

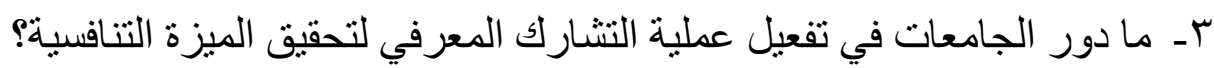


عـ - ما التوصيات والمقترحات الإجر ائية لتفعيل التشارك المعرفي بين أعضاء هيئة التدريس لتحقيق الميزة التنافسية بالجامعات المصرية؟ الإجراته

أهداف البحث

$$
\text { هدف البحث إلي تحقيق ما يلي: }
$$

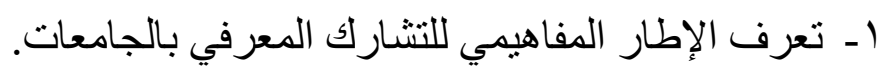
r- بـ تحديد الأسس النظرية للميزة التنافسية بالجامعات.

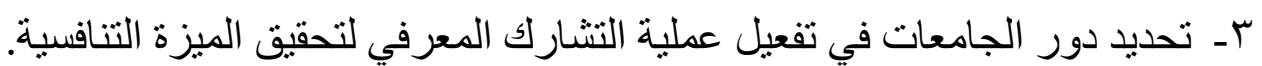

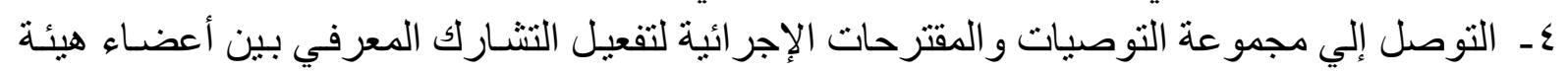
التدريس لتحقيق الميزة التنافسية بالجامعات المصرية.

\section{أهمية البحث}

$$
\text { تنبعث أهية البحث من الآتي: }
$$

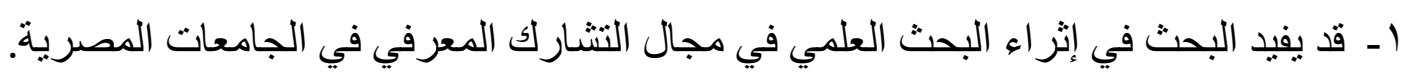

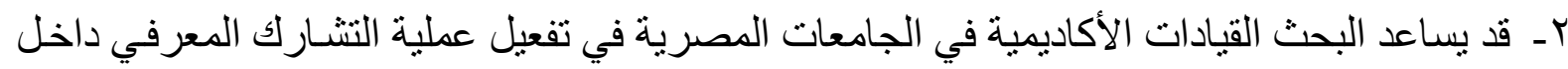

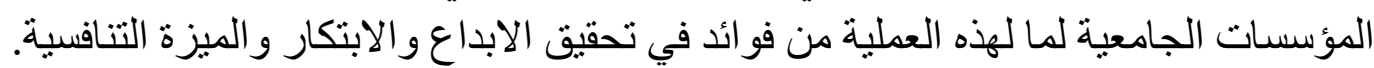

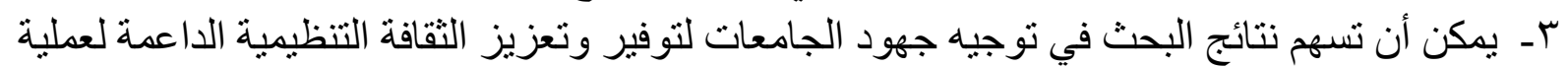

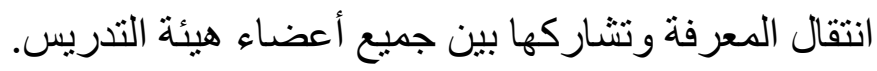
ع ـ قد يفيد البحث أعضاء هيئة التدريس في التعرف علي التهاء هينة التبديات التي تعوق عملية التشـارك المعرفي وكيفية التغلب عليها.

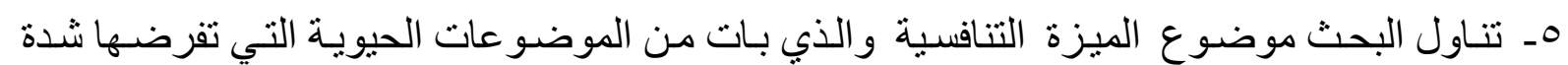
المنافسة بين الجامعات، والتأكيد على أن تنافسية الجامعة جزء هـ لا لا يتجز أ من تنافسية الدولة. منهج البحث اعتمد البحث على المنهج الوصفي الذي لايقتصر على جمع المعلومات و البيانات عن ظـاهرة

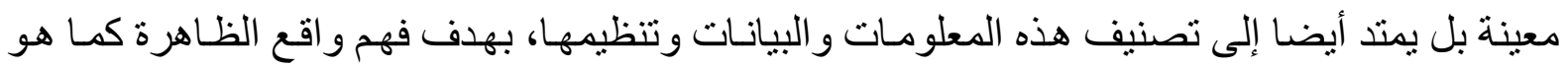

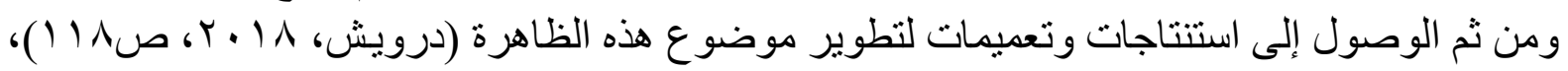

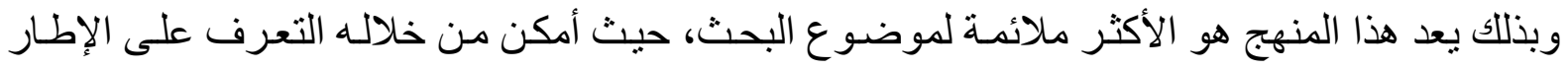

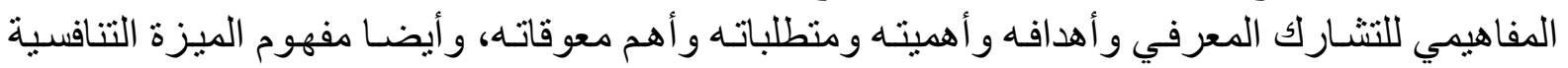
وخصائصها و استر اتيجياتها و أهميتها و أهدافها. مصطلحات البحث: تحددت مصطلحات البحث فيما يلي:

ا ـ التشارك المعرفي:"Knowledge Sharing" التشارك لغة يعني التعاون و التضـامن في انجاز العمل علي قدم المسـاو اة وهومصدر للفعل "تثـارك"

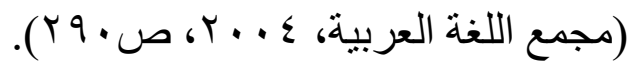


أما اصطلاحا فيعرف التثارك المعرفي بأنه "تطبيق معتمد ونقل للأفكار و الآراء و الخبر ات من شخص

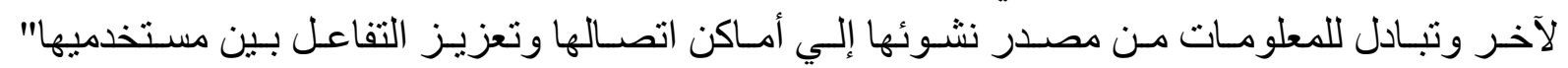

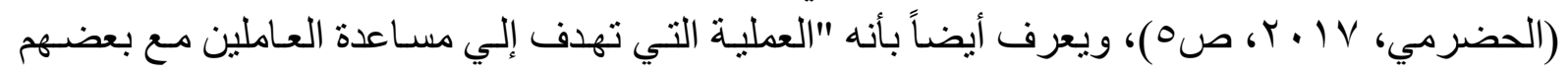

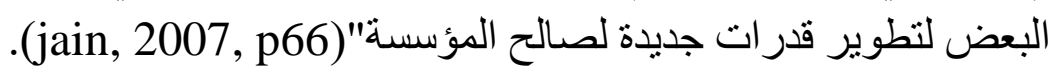

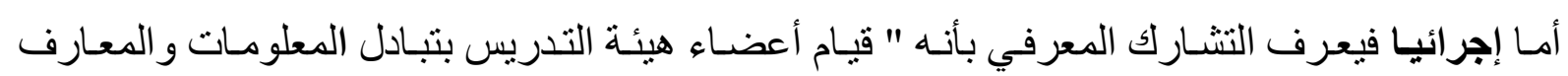

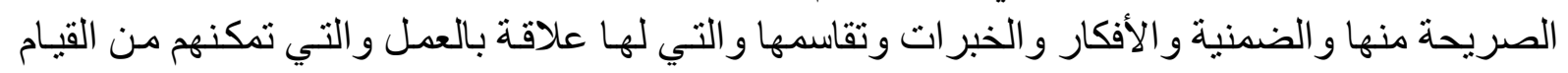

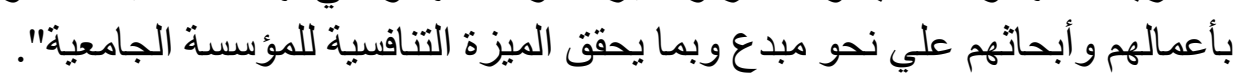

\section{rـ الميزة التنافسية:"Competitive Advantage"}

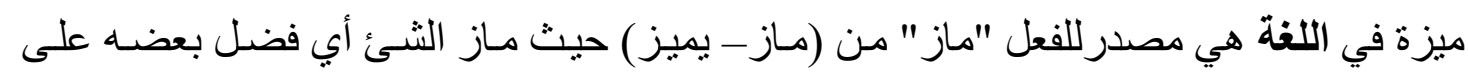

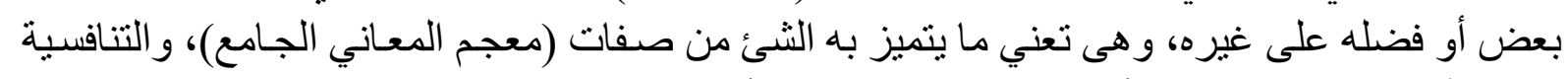

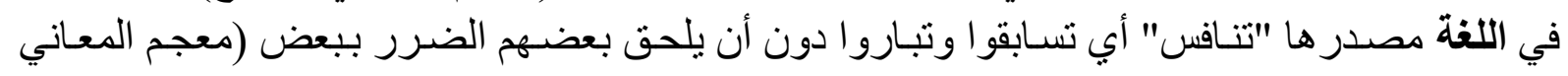
الجامع).

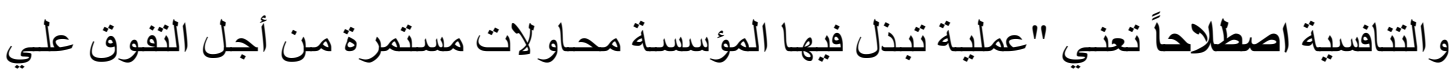

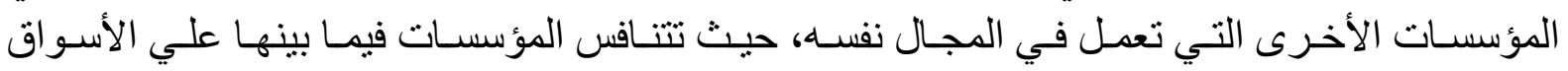

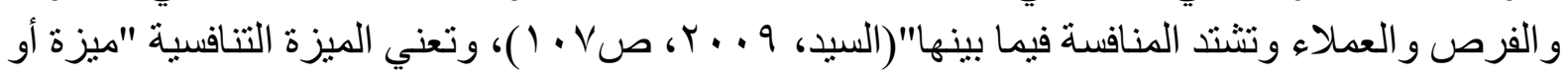

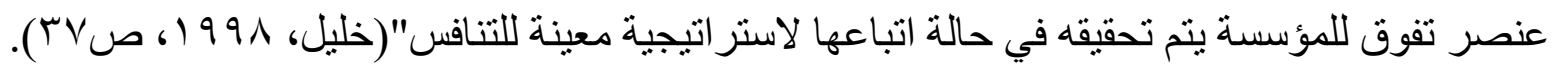

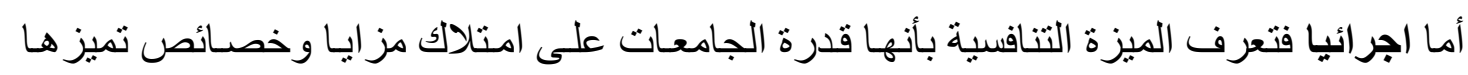

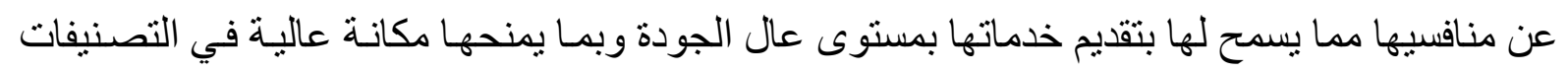

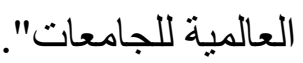

الدراسات السابقة

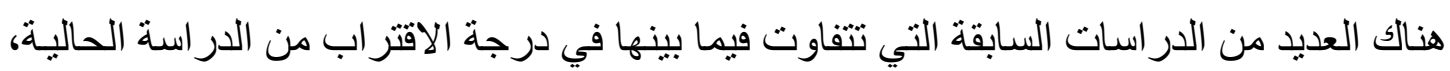

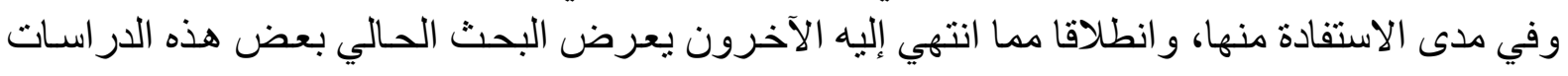

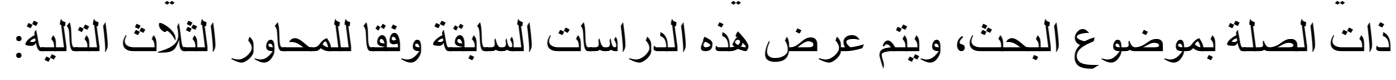
المحور الأول: دراسات تتعلق بالتشارك المعرفي:

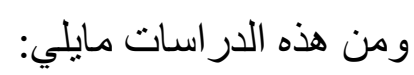

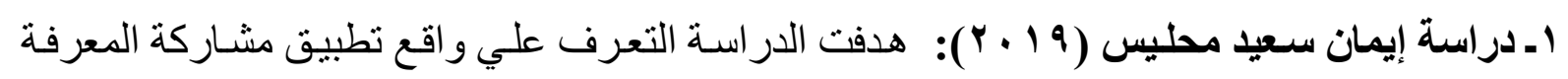

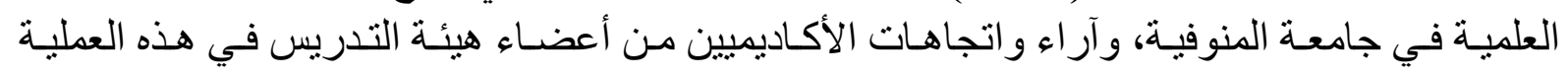

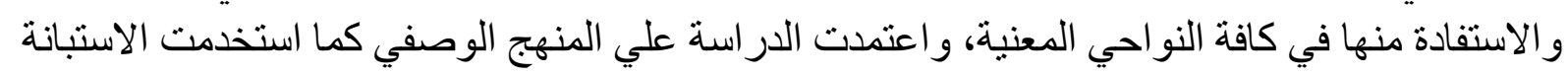

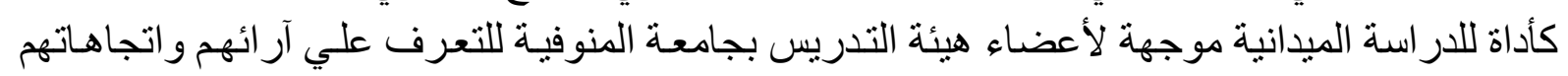

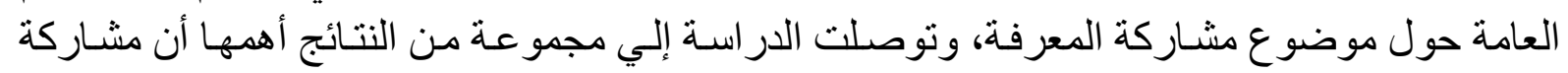

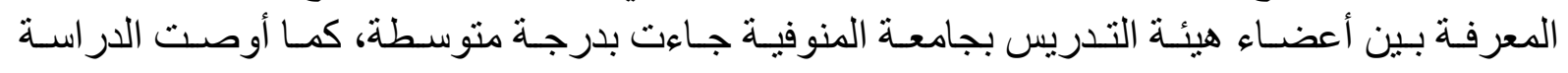

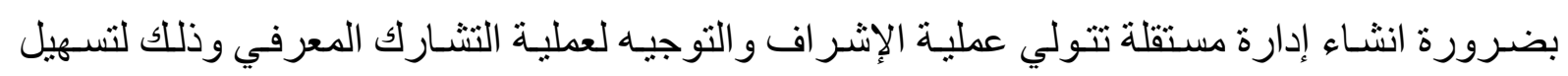




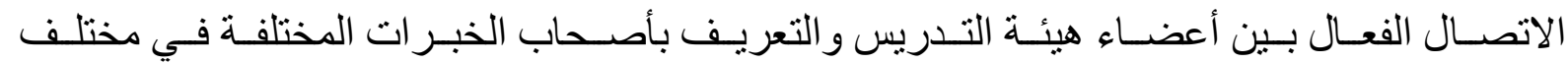

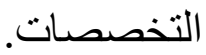

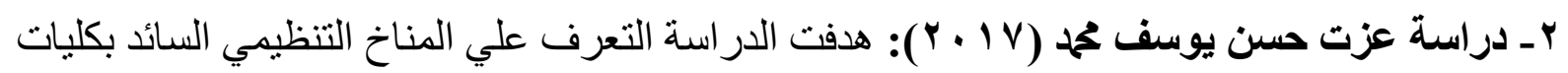

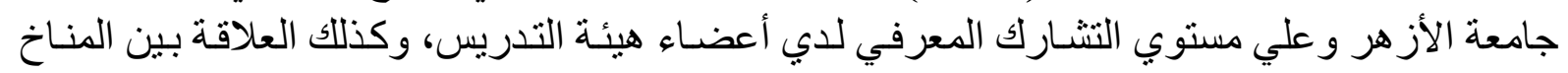

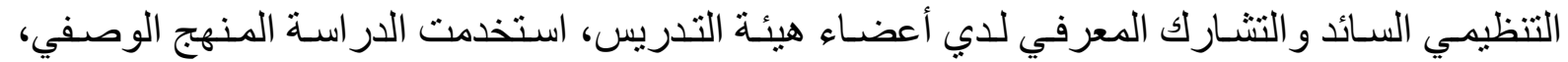

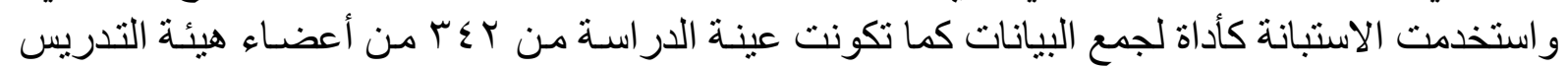

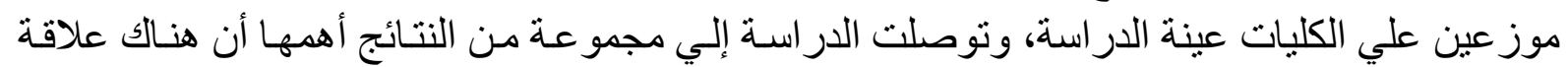

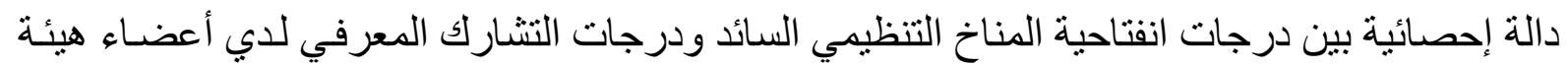

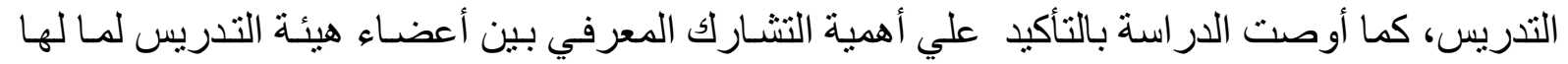

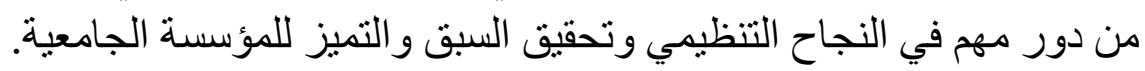

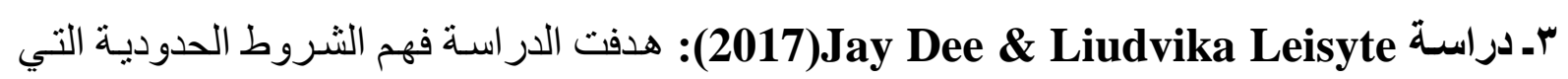

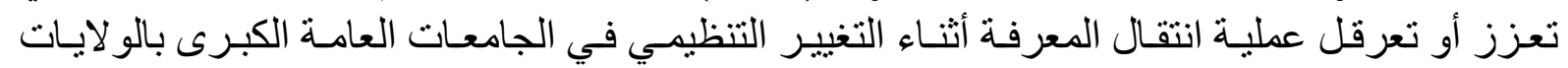

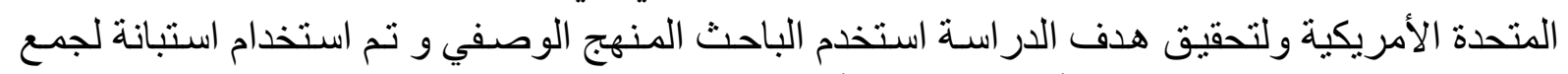

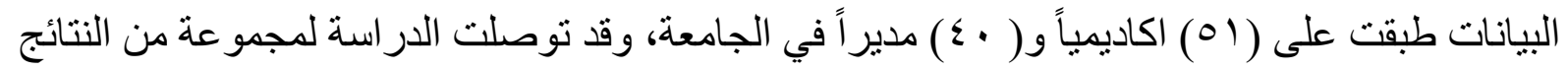

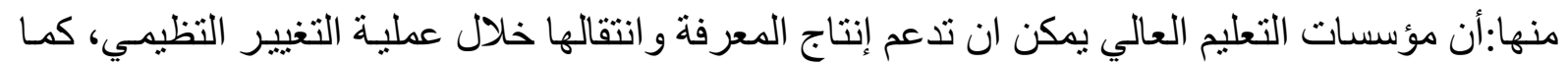

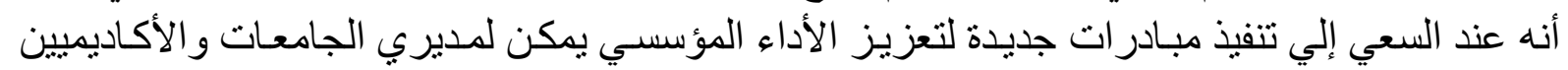

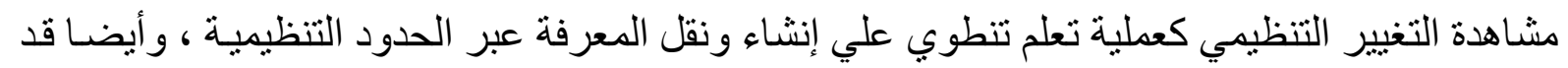

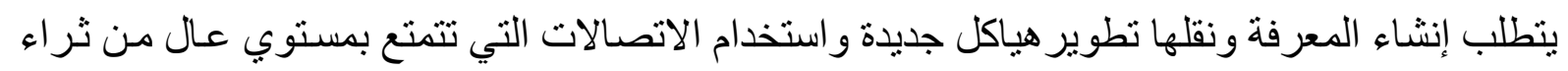

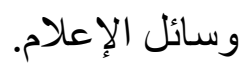

المحور الثاني: دراسات تتطلق بالميزة التنافسية:

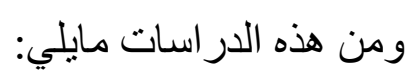

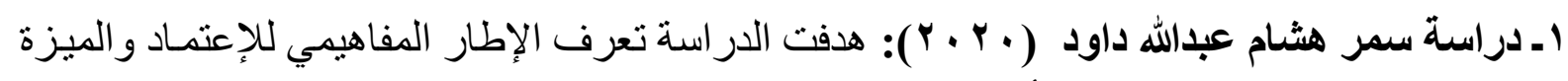

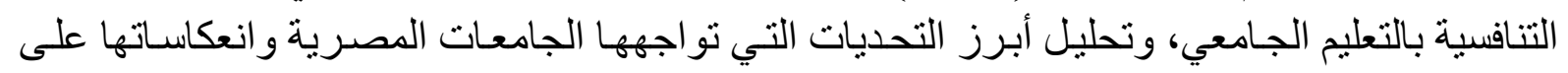

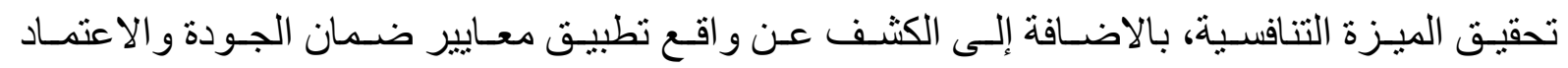

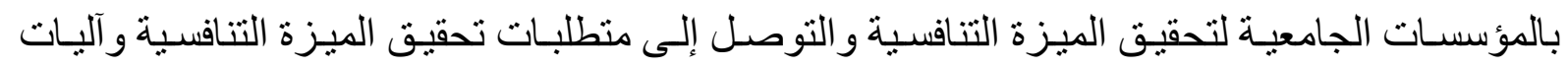

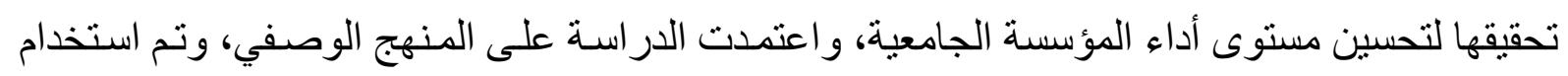

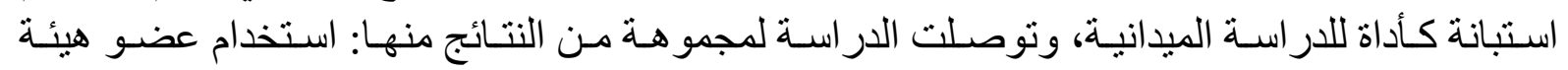

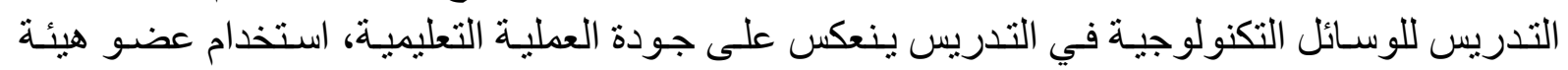

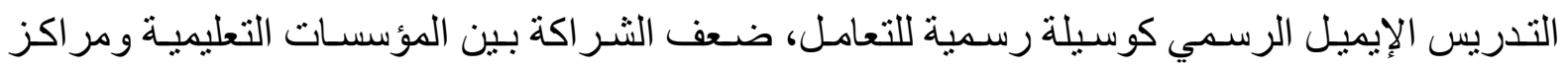

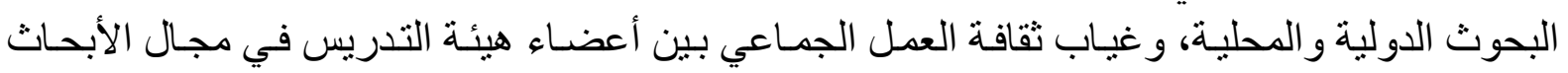

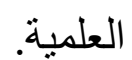

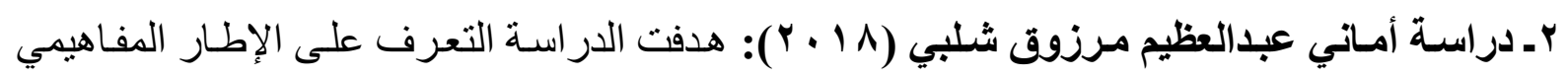

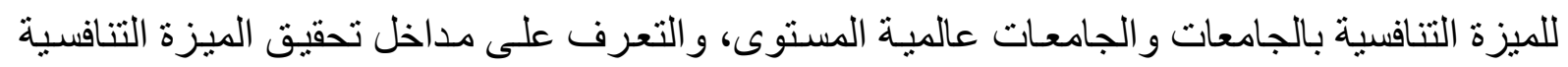




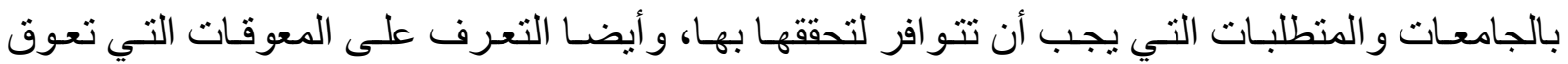

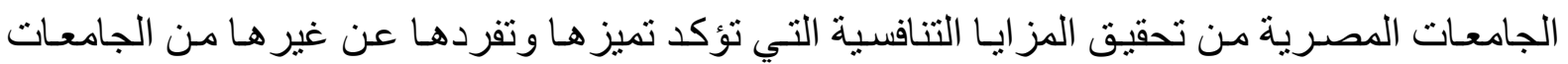

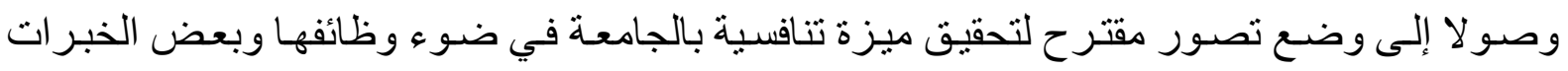

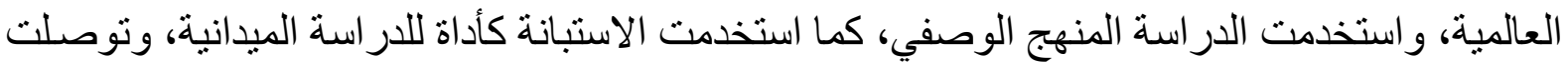

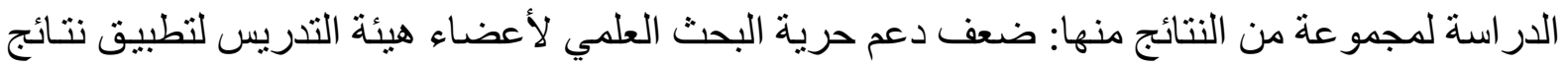

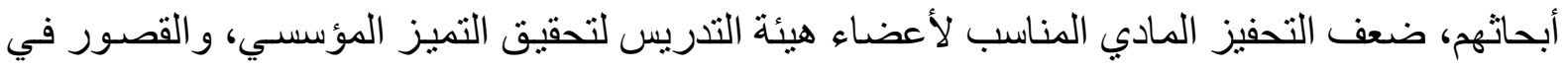

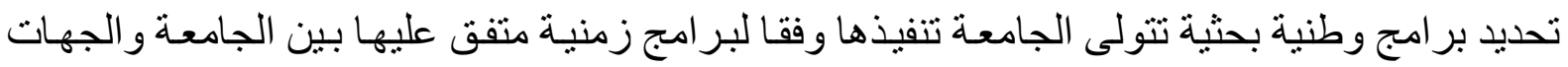

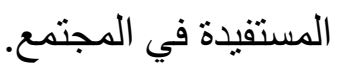

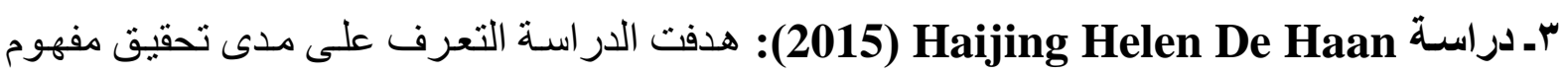

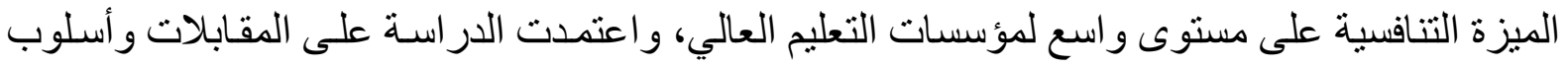

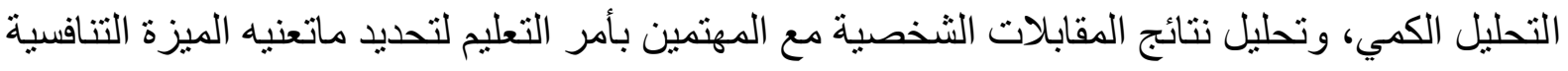

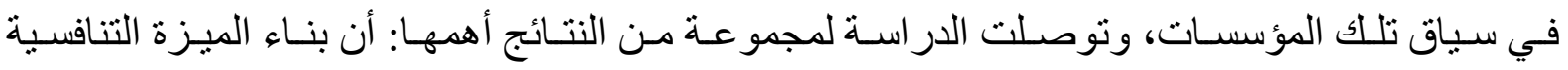

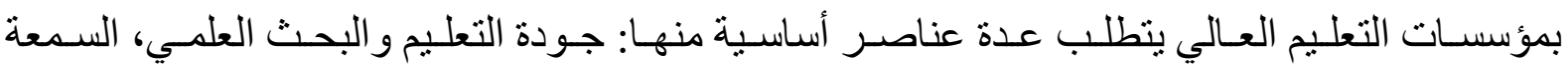

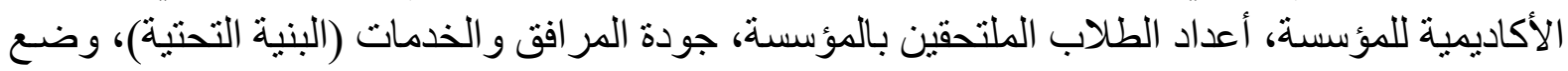

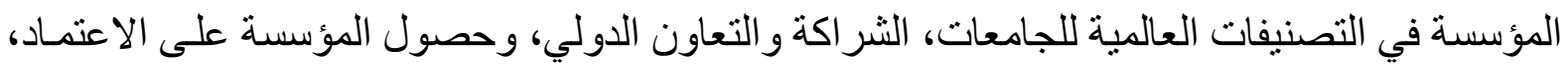

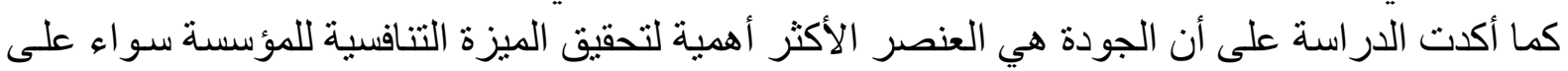

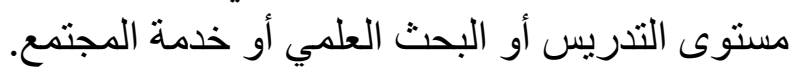

المحور الثالث: دراسات تتعلق بالتثارك المعرفي والميزة التنافسية: ا ـ دراسـة Rosa Eidizadeh et al

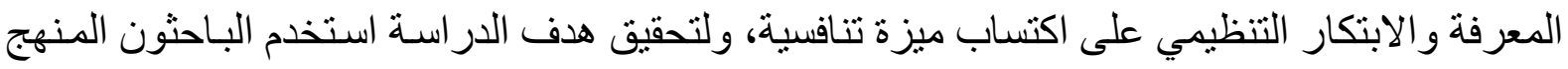

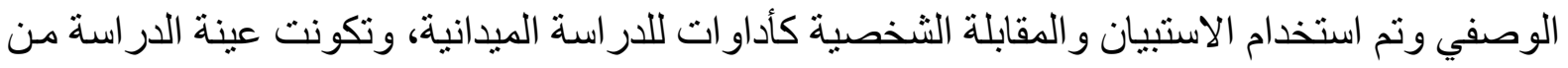

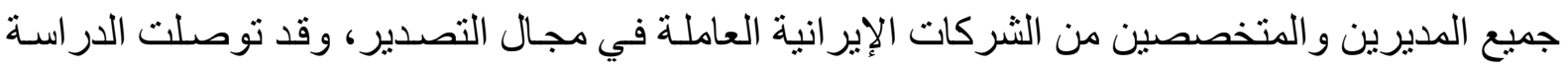

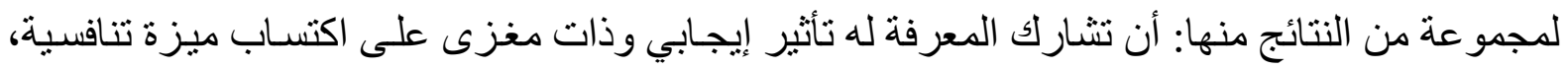

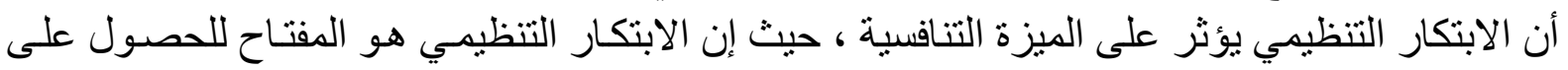

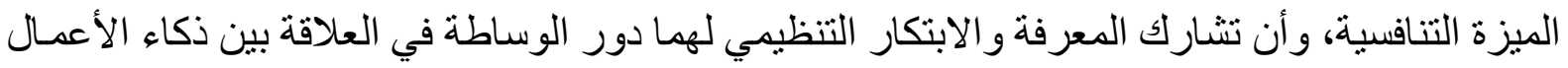

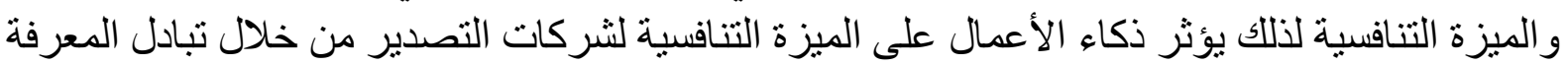
والابتكار التنظيمي.

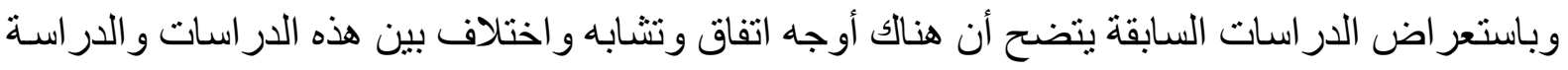

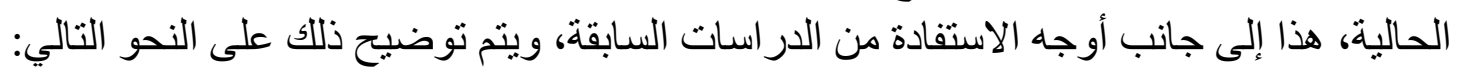

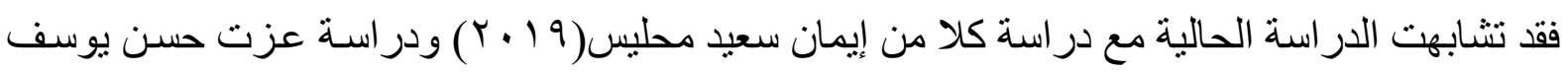

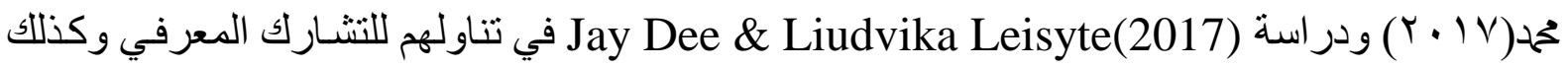

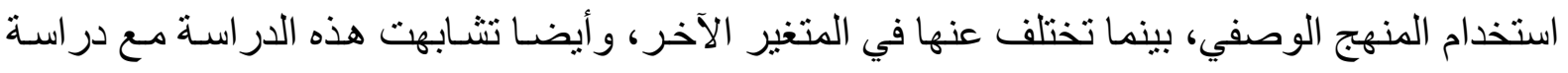

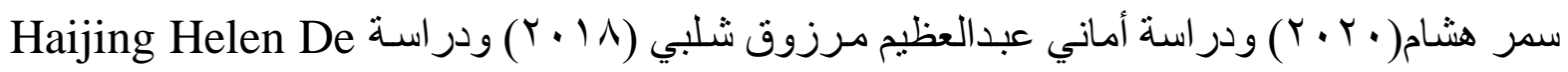




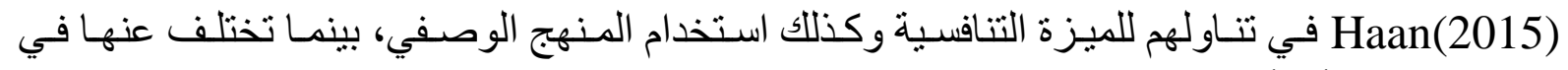

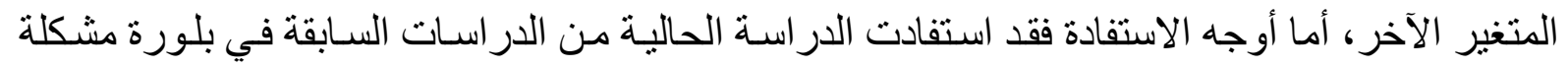
البحث وصياغتها. محاور الدراسة وصياعة

يسير البحث وفقا للمحاور التالية:

\section{المحور الأول:الإطار المفاهيمي للتثشارك المعرفي}

ا ـ مفهوم التشارك المعرفي:

يعد التثارك المعرفي أحد عمليات إدارة المعرفة و أكثر ها أهية، وذللك لأن عملية توليد الماركية المعرفة

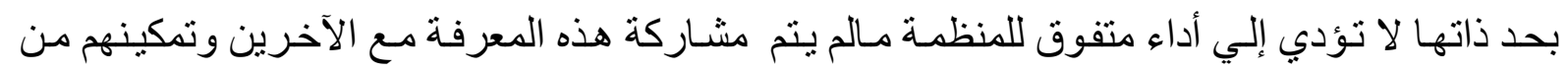

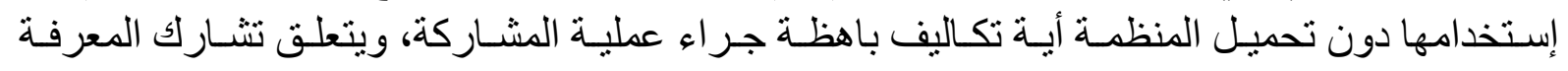

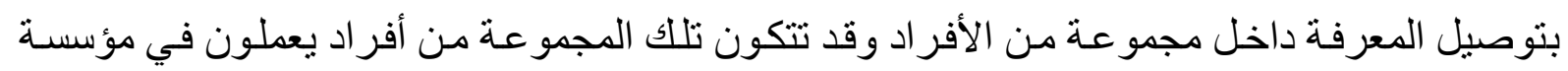

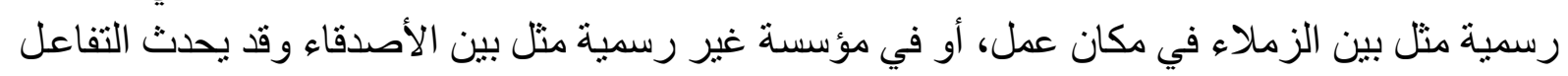

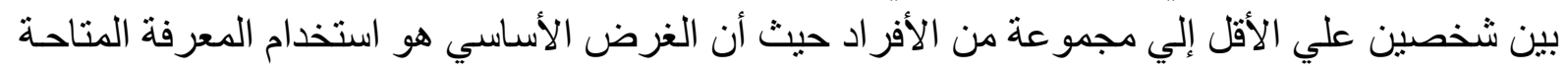
لتحسين أداء المجمو عة (Ching et al, 2008, p317).

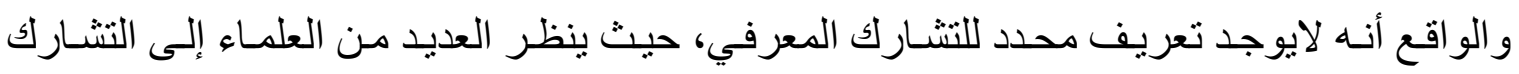

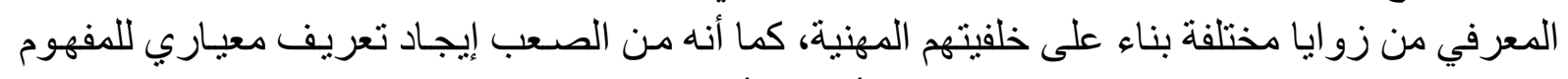

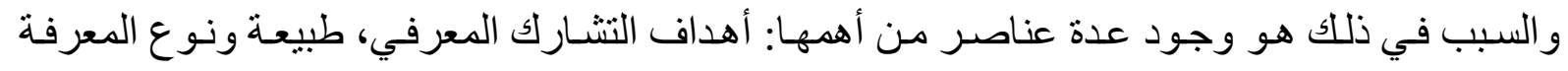

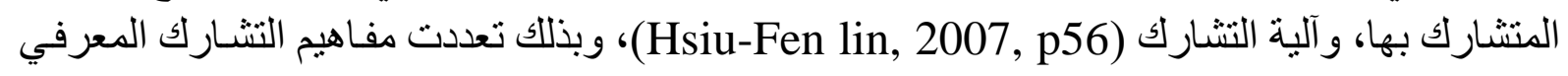
ومنها:

- - تبادل المعلومات و النصائح و الخبرات المتعلقة بالعمل لمساعدة الآخرين و التعاون معهم لتنفيذ تلكي الأعمال وحل المشكلات وتطوير أفكار جديدة(Bochang, 2018, p42).

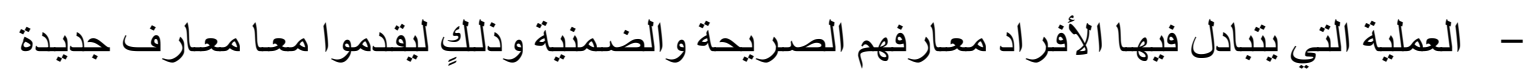
. (Santosh \& Panda, 2016, p 248)

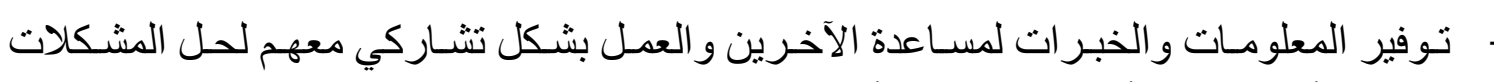
وتطوير أفكار جديدة أو تنفيذ سياسات أو اجر اءات (Wanger,2003, p 98).

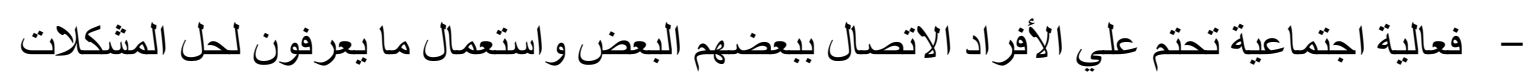
بشكل خلاق لضمان استمر اريتهم في أعمالهم اليومية (Zheng, 2018, p53).

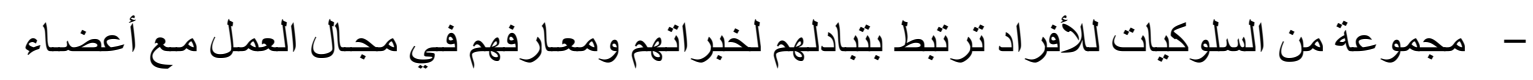
المؤسسة الآخرين (Yang, 2007, p78). ومن خلال التعريفات السابقة للتشارك المعرفي يمكن استتباط بعض النقاط المهمة و التي تقوم الباحثة بتوضيحها على النحو التالي: 
ل التشارك المعرفي هو سلوك فردى أو جماعي . $\checkmark$

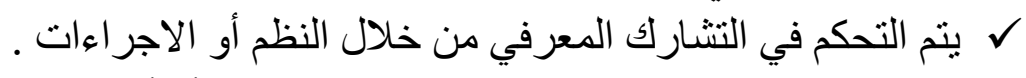
ل لتيجة التشارك المعرفي تكون مشتركة بين طرفين أو أكثر.

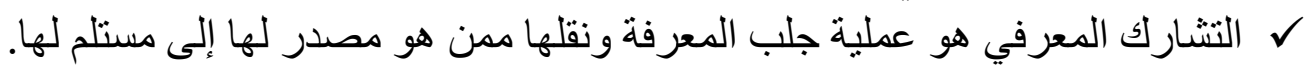

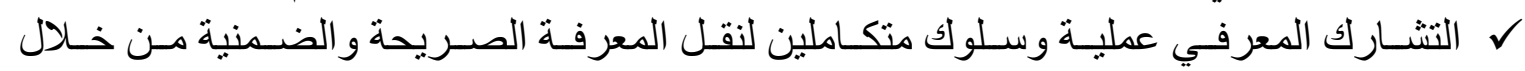
الاتصالات و التفاعلات بين الأفر اد.

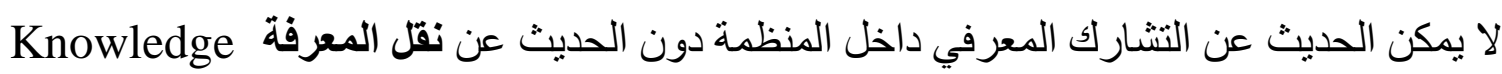
Transfer

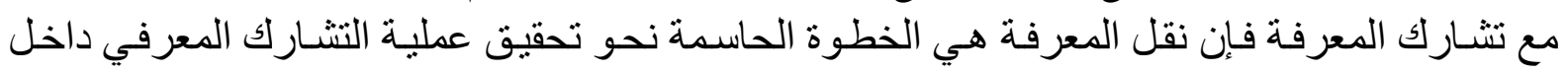

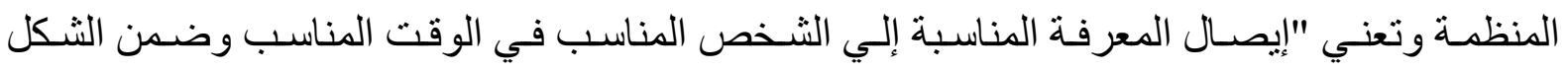
و التكلفة المناسبة" (Akbar et al, 2012, p209).

\section{r - ـ أهداف التثارك المعرفي}

يضمن التشارك المعرفي بشكل أساسي تميز الجامعة وذللك لأنه يدعم عمليات الإبداع و والابتكار

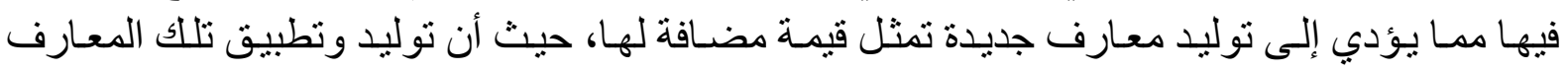

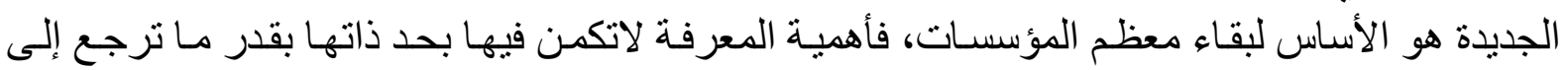

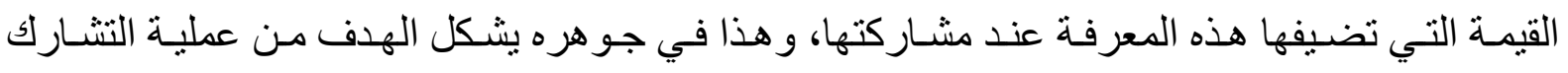
المعرفي و التي تتمثل في (Ugochi et al, 2013, p720): أ ـ تحسين القدرة الاستيعابية وتحقيق القدرة على الابتكار و القدر ات الأخرى.

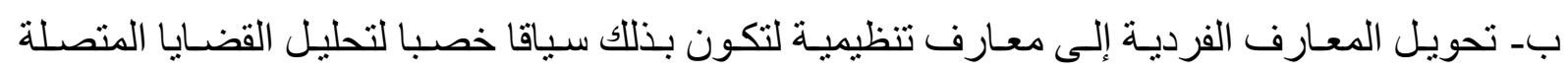
بالمستوى الهيكلي. ج- تطوير المسار المهني لعضو هيئة التدريس من خـلال كسب سمعة مهنية واعتر اف داخل الجامعة

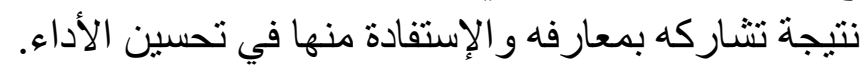

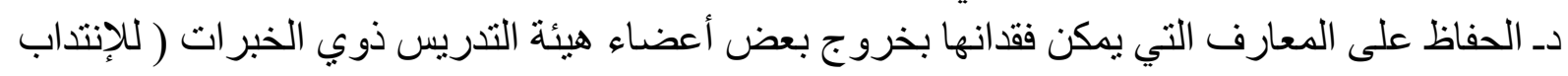
أو الإعارة مثنلا).

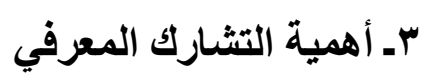

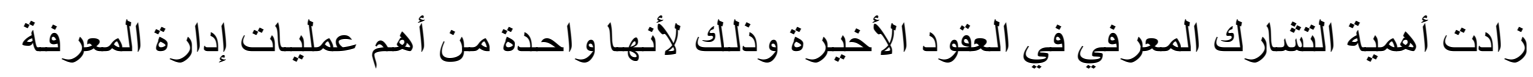

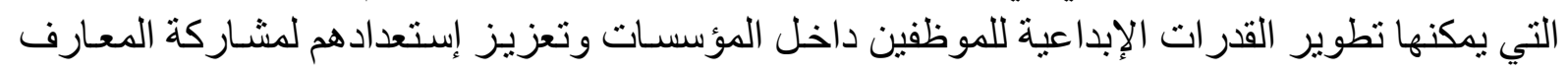

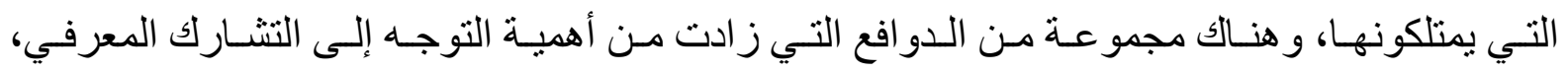

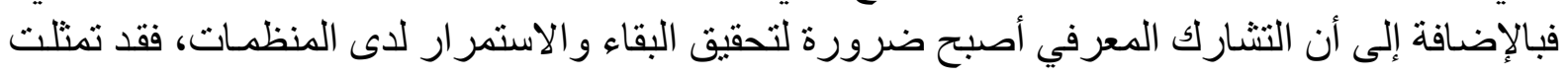
في (Gurteen, 2000, p2): • أخذت المنتجات غير الملموسة (الأفكار، العمليات و المعلومات) حصـة كبيرة ومتز ايدة في التجارة

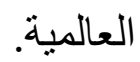


ضمان الميزة التنافسية المستدامة يتوقف على الابتكار المستمر، وبعبارة أخرى تطبيق المعرفة الجديدة. ارتفاع معدلات دور ان العمل، إذ أن الموظفين يرفضون البقاء في نفس الوظيفة مدى الحياة، ومغادرة

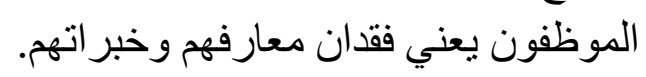

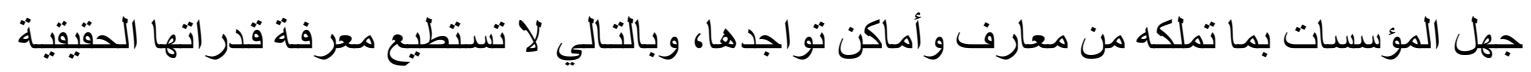

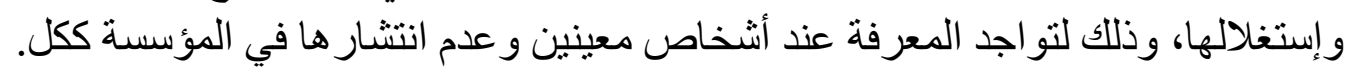

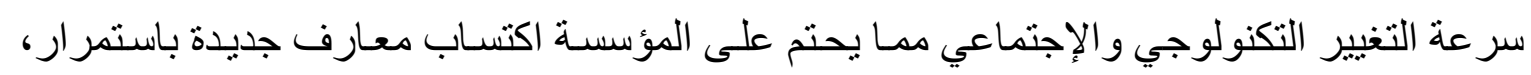

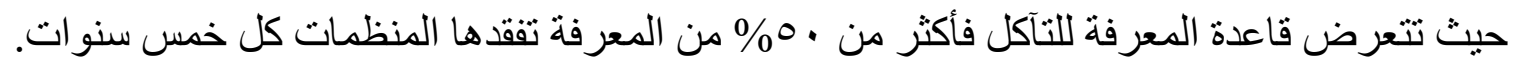

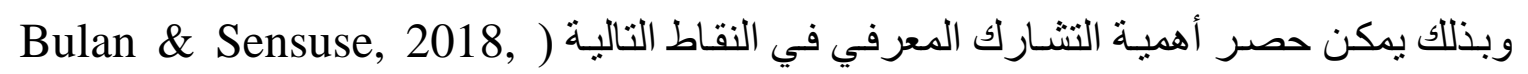

أـ يعزز الأداء الكلي للمنظمة وكذلك العلاقات الاجتماعية بين الموظفين. ب-يتيح للأفر اد حل المشكلات بسر عة أكبر و الحد من الإزدو اجية المكاعة المكلفة من الجهد و إيجاد حلول مبتكرة من خلال التعاون. ج-يسهم التشارك المعرفي في تحقيق التعلم الفردي و التنظيمي.

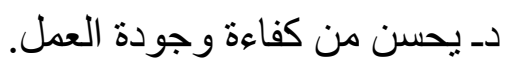
هـ-تحقيق ميزة تنافسية للمؤسسة. و - يؤكد التثارك المعرفي على على أن المنظمة ستبقى دائما مرنـة و أكثر ديناميكية لمو اجهة أي تغييرات في

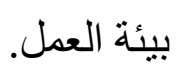
زـ تحقيق العديد من النجاحات التنظيمية نتيجة تطبيق المعارف الجديدة. ــ وسائل وأساليب تحقيق التشارك المعرفي: زئي

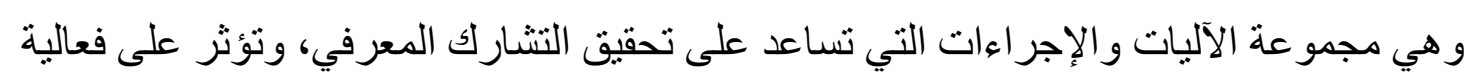

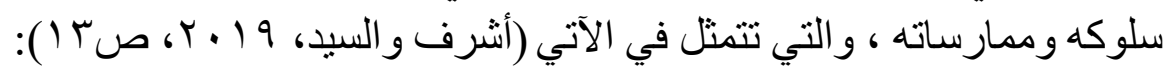
أـ مشاركة المعر فة من خلال قاعدة بيانات المؤسسة.

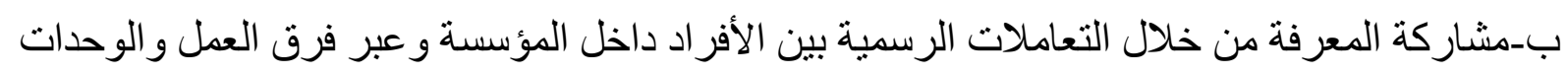
التنظيمية بها. ج-مشاركة المعرفة من خلال تفاعل الأفر اد غير الرسمي مع بعضهم البعض.

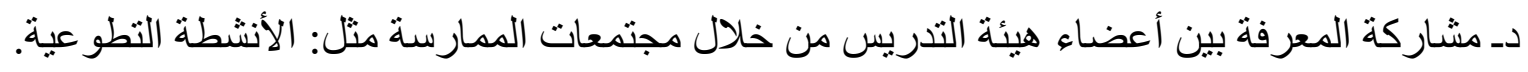

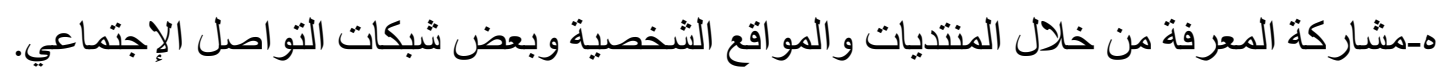

أي أنه يمكن حصر تلك الآليات و الأساليب في النقاط التالية (Ozbek \& Toplu, 2011, p23): - الآليات الرسمية: وهي تلك الأساليب التي تشرف عليها الجامعة مثل التقارير و المذكرات و النشرات الدورية.

- الآليات غير الرسمية: وهي تلك الأسـاليب غير المبرمجة في الجامعة كاللقاءات التي تنتم خـارج

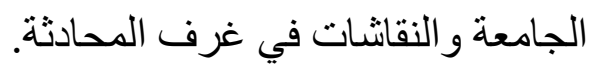




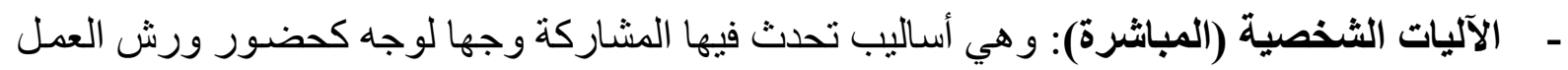

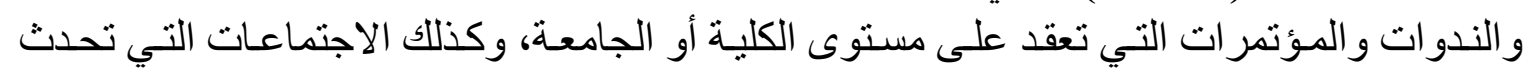

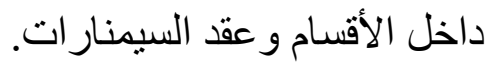

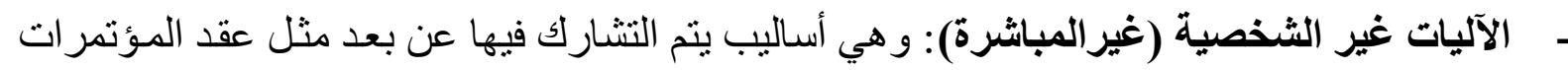

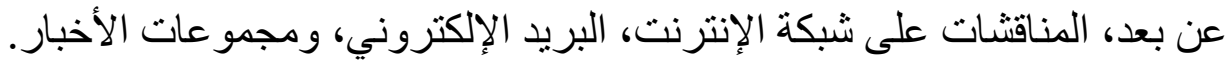

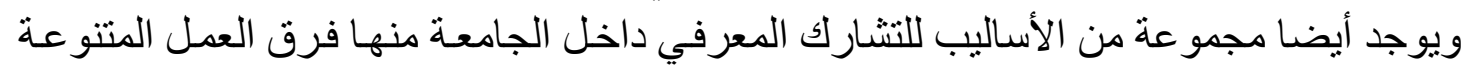

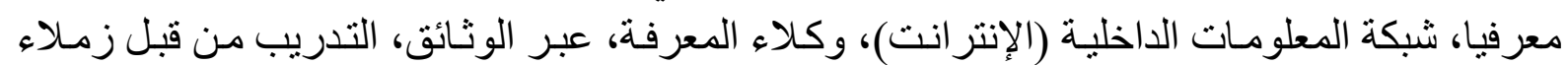

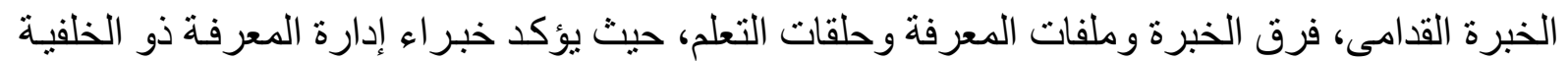
التعليمية على أن التدريب يعزز معرفة الخيرة ملفات المستخدمين(Shaqrah et al, 2011, p 54). هـ منطلبات تحقيق التثارك المعرفي :

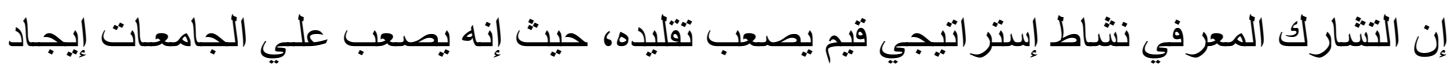

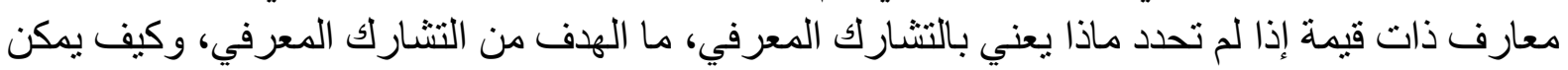
تقييم عملية التشارك المعرفي وتحسينها.

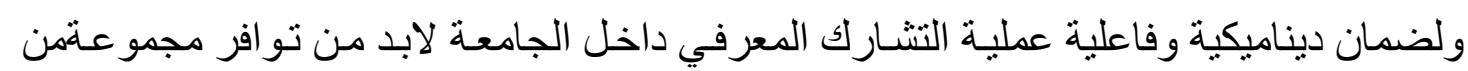

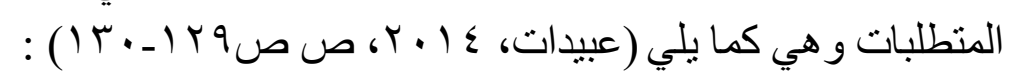
أـ الهيكل التنظيمي المناسب: بدون تبادل المعلومـات و المعارف و والأفكار بين الأفر اد داخل المؤسيسة

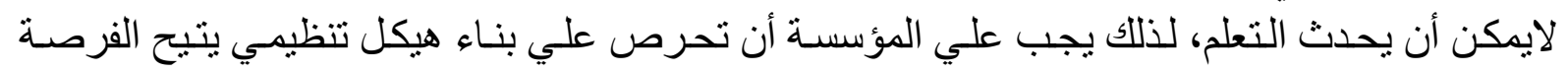

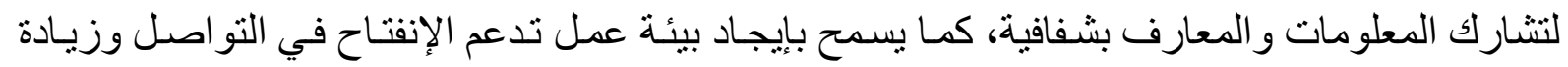

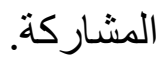

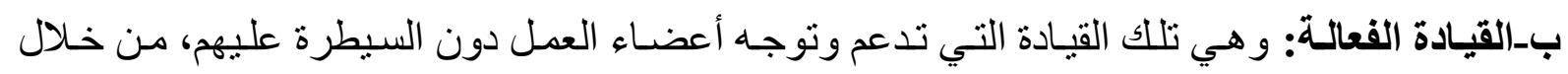

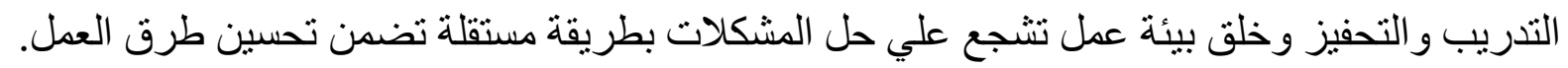

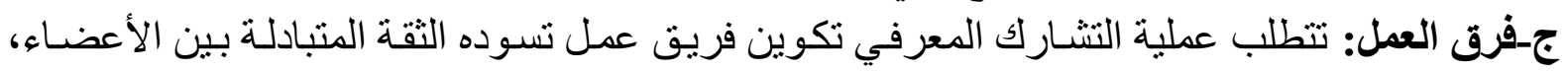

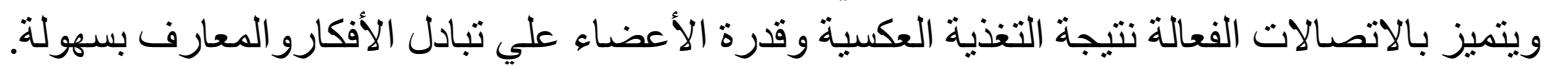

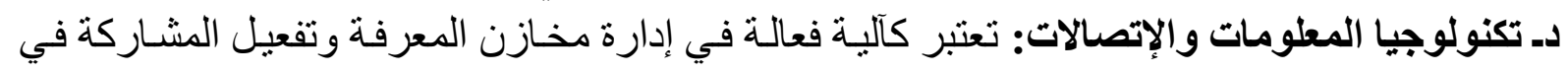

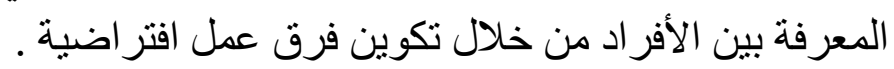

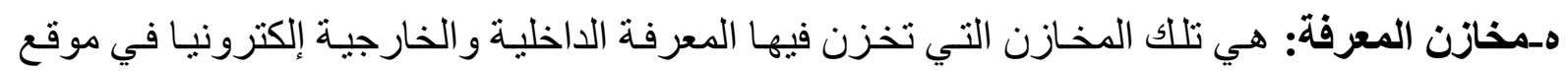

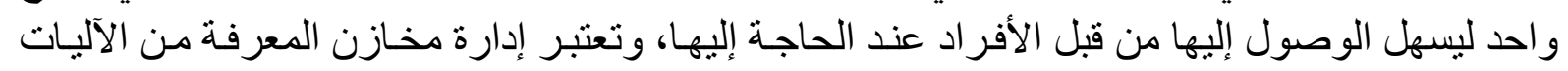

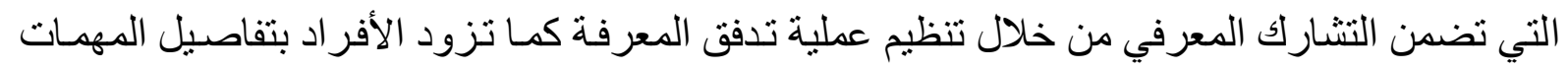

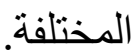
وـ التدريب: لابد من الاهتمـام بتدريب العاملين علي استخدام الوسائل و الأدوات المتخصصـة في نظم

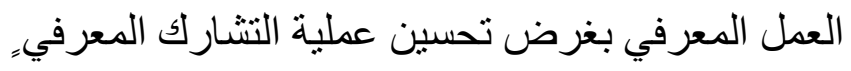

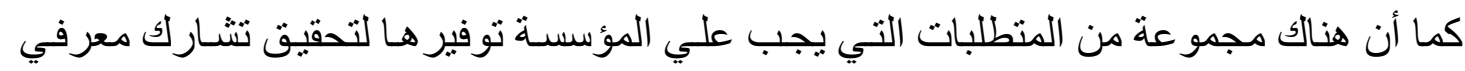

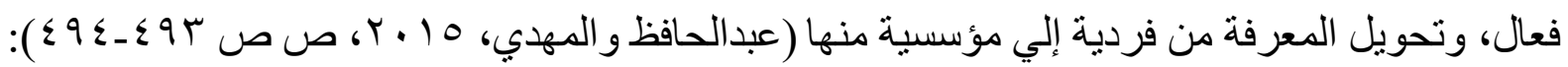

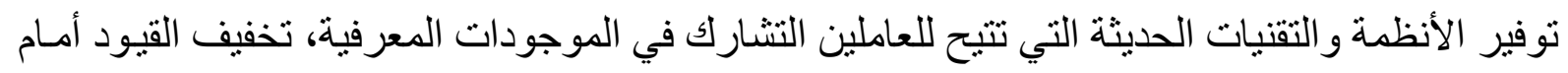
-11 - 


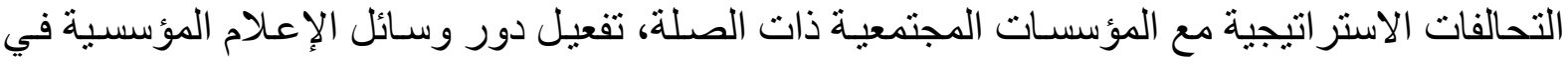

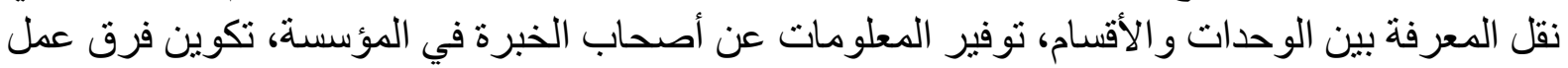

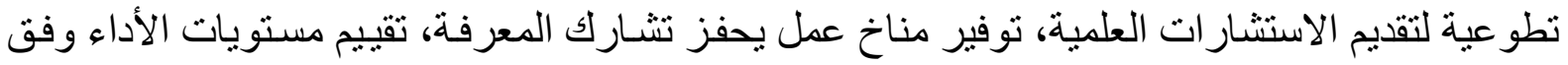
نظم تثارك المعرفة، وتسهيل الوصول إلي قو اعد المعرفة التي تمتلكها المؤسسة. דـ معوقات التشارك المعرفي في الجامعات:

هنالك العديد من المعوقات التي تعوق عملية التشارك المعرفي، منها:

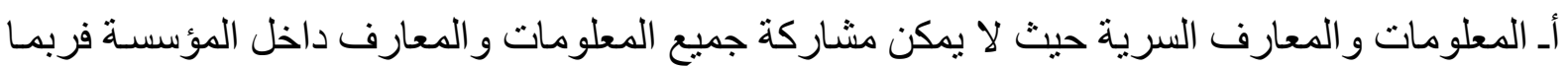

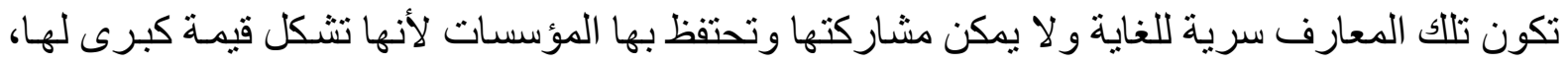

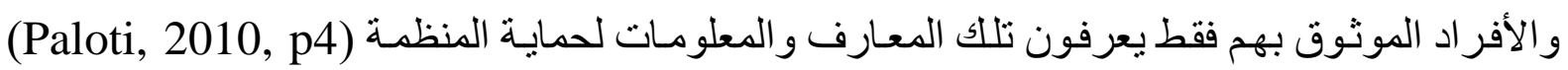
و) و (Rusuli \&Tasmin, 2010, p800).

ب ب ـ غياب ثقافة النتشارك المعرفي على المستوى المؤسسي ( Mazleena \& Noorminshah, 2011, .(p80

Saravanan ( م ـ عدم تقدير البعض للمعرفة مماينتج عنه شعور ا يمنعهم من سلوك التشـارك المعرفي .(et al, 2017, 34

Ismail \& ( د عدم تو افر الثقة، الاختلافات في الثقافة الوطنية أو العرقية، اختلاف مستوى الخبرة .(Yusof, 2010, p3 ه ـ ضعف البنية التكنولوجية، عدم الأمان الوظيفي (Koivisto, 2018,p 29).

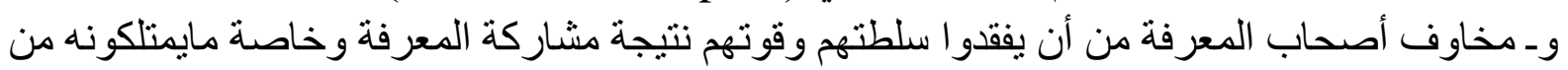

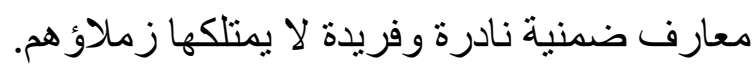

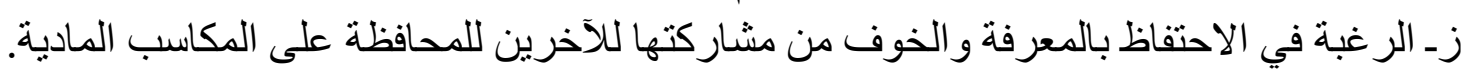

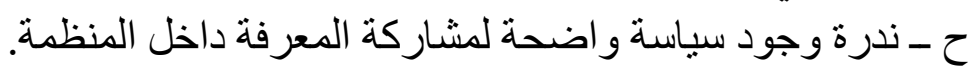

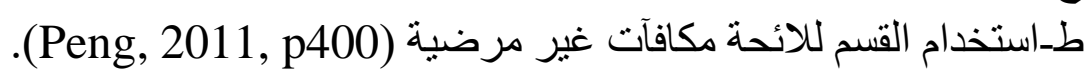
ي-تندي كفاءة تقنية المعلومات و الإتصالات ألفات المستخدمة.

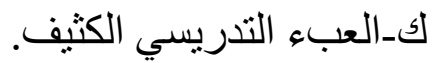
ل-غياب وسائل التشجيع و التحفيز المناسبة. المحور الثاني: الأسس النظرية للميزة التنافسية

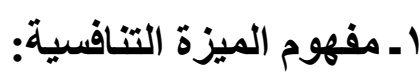

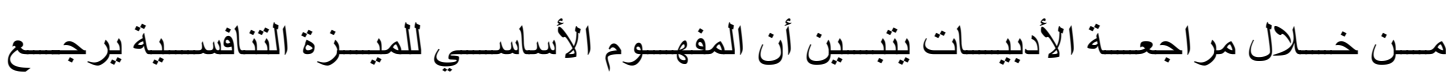

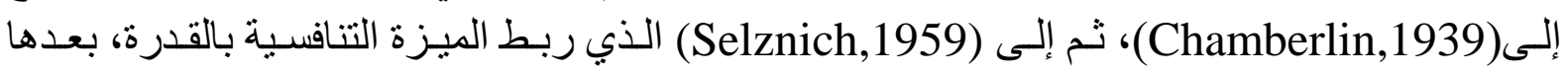
حصل تطور في هذا المفهوم حين وصف كل من ( Schendel \& Hofer) الميزة التنافسية بأنها:"

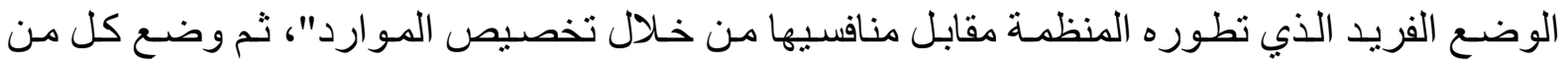
الجيل التالي من الصياغة المفاهيمية للميزة التنافسية، إذ اعتبر ا أنها

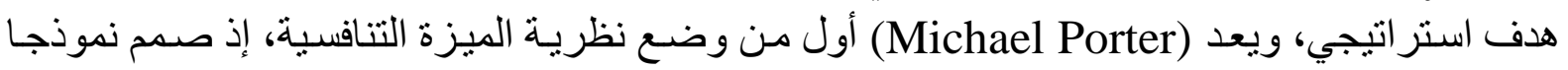




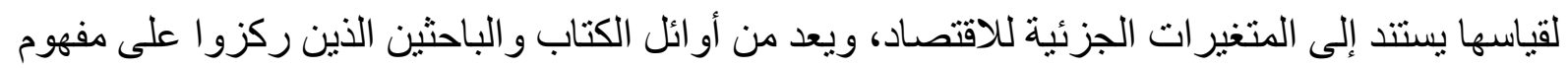

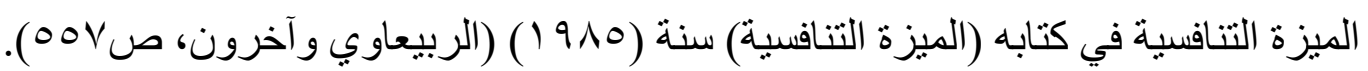

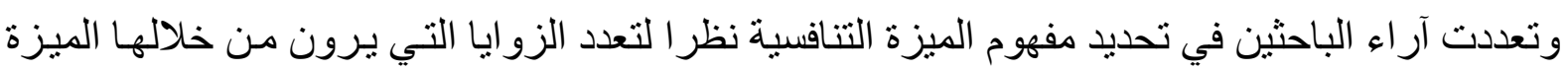

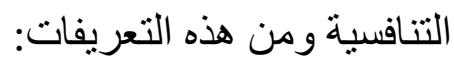

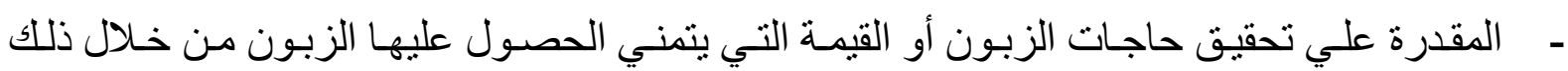

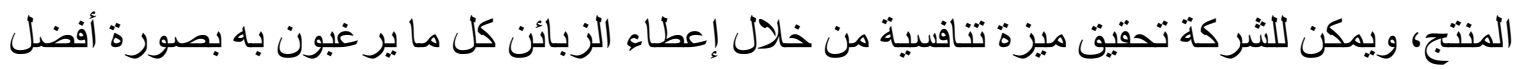

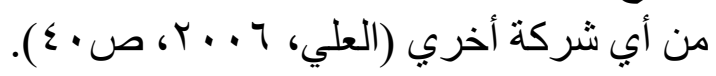

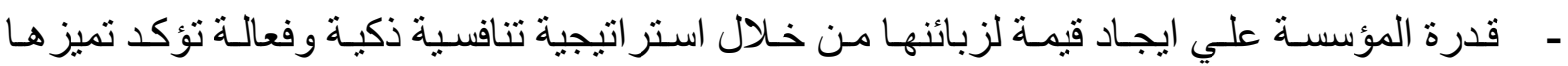

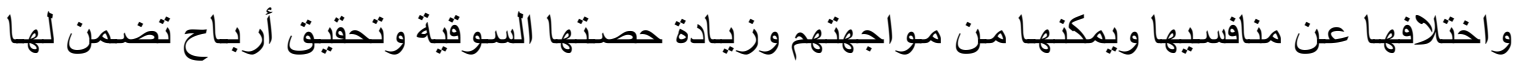

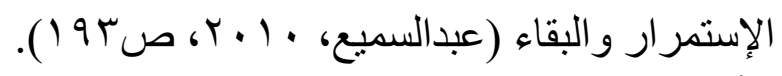
- الأفضلية علي المنافسين و التي يتم تحقيقها من خلال تقديم قيم للمستهلكين أكثر من القيم التي يقدمها

المنافسون (Sadalia et al, 2020, p238).

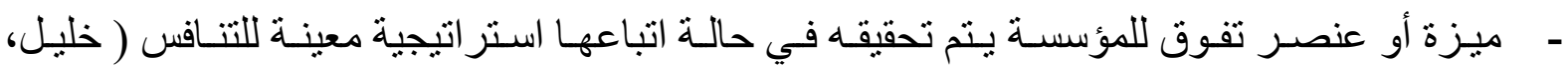
(TV TV

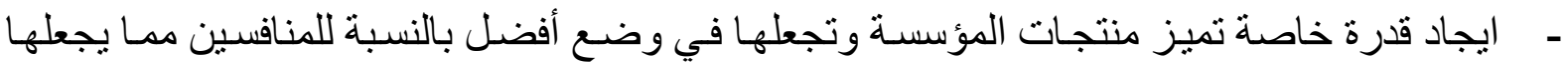

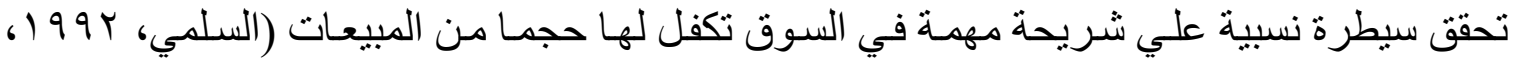

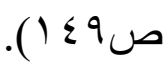

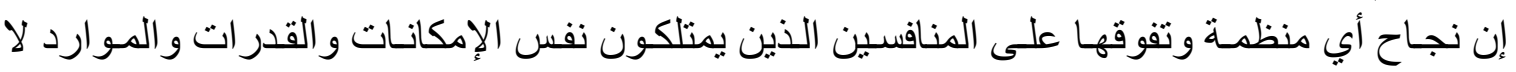

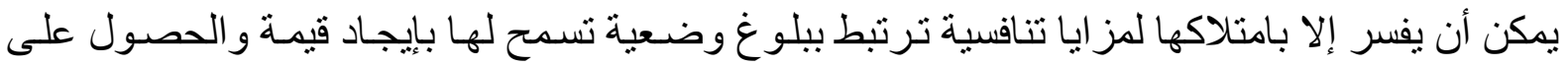

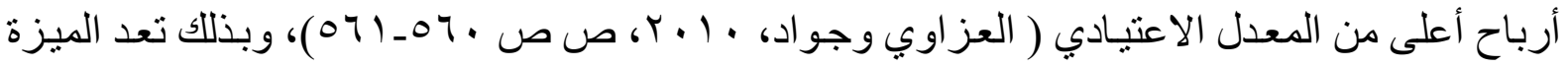

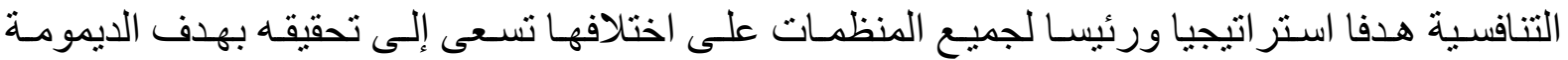

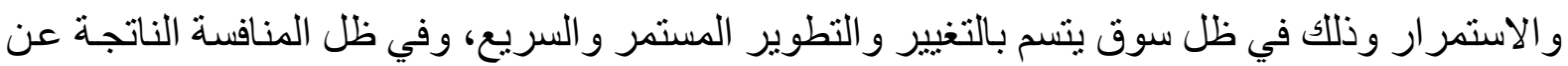

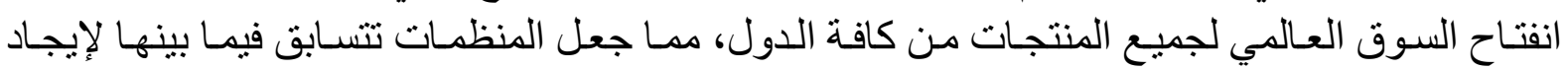

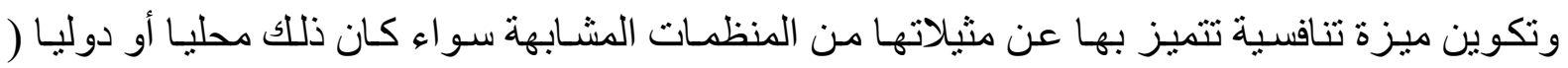

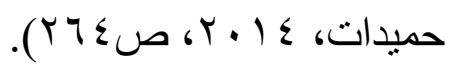

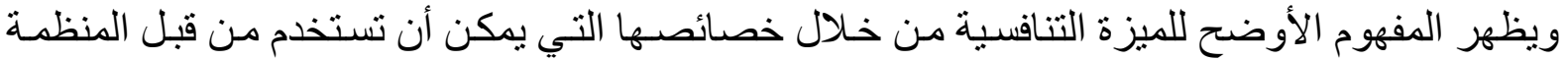

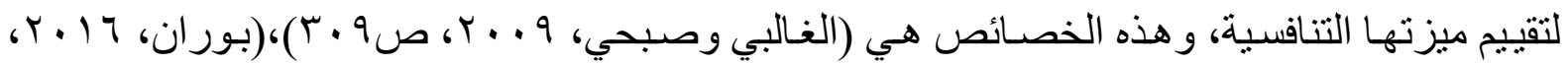

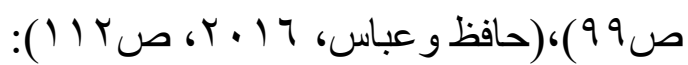

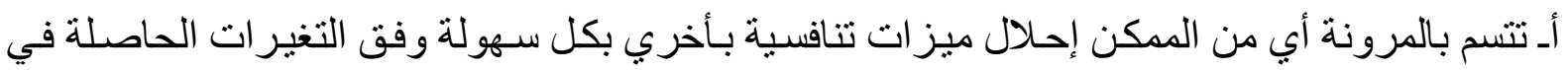
البيئة الخارجية. ب-تتسم بالنسبية مقارنة بالمنافسين أو مقارنتها في فتر ات زمنية مختلفة وليست مطلقة. ج-تصدر من داخل المؤسسة وتعمل علي إيجاد قيمة لها. 
دـ تتسم بالاستمر ار و الاستدامة أي تحقق للمؤسسة السبق علي المدي الطويل وليس علي المدي القصير

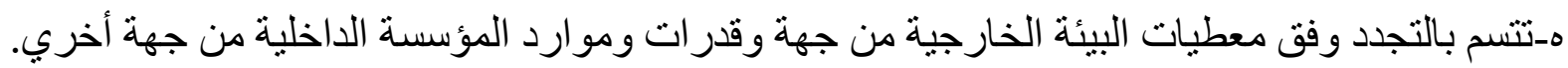
و - تبني الميزة التنافسية علي الاختلاف وليس علي التئي التنابها.

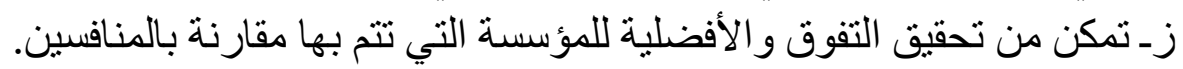

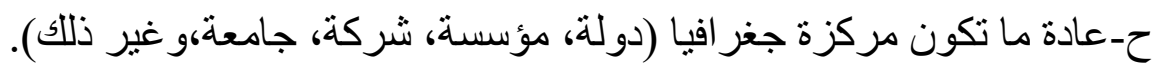

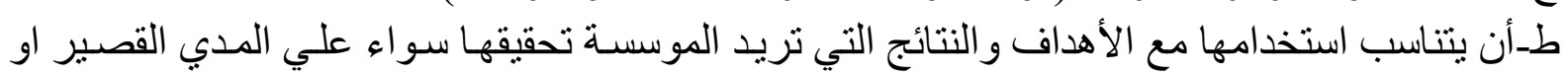

\section{r- استر اتيجيات تحقيق الميزة التنافسية:}

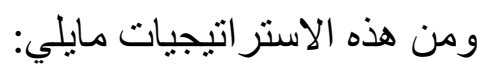

أـ استراتيجية قيادة التكلفة

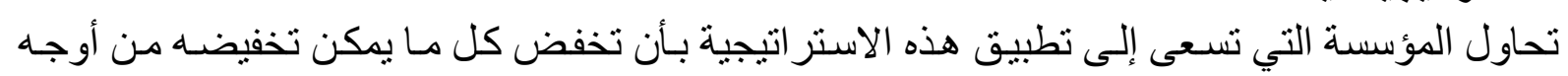

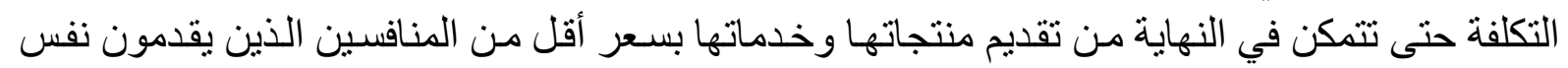

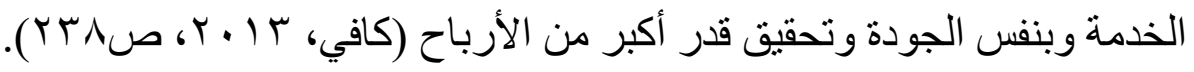

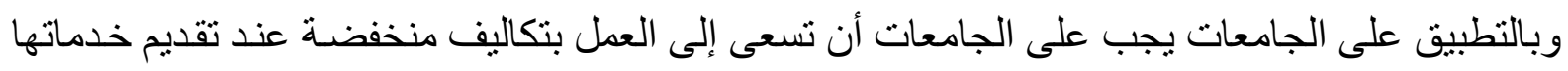

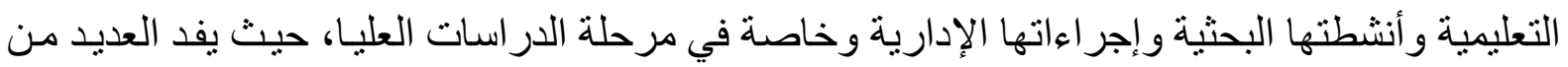

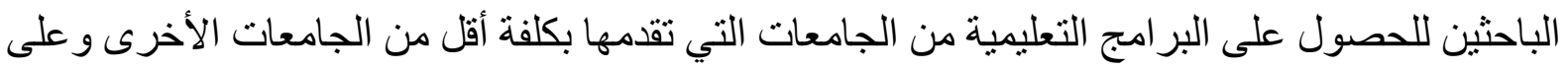

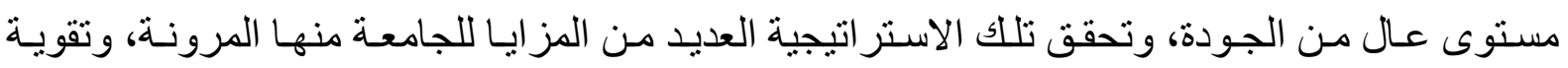

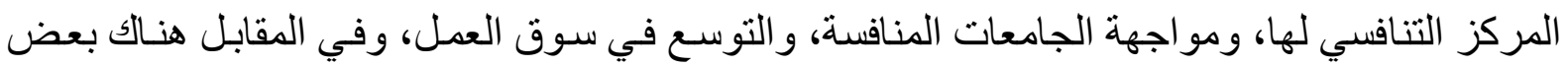

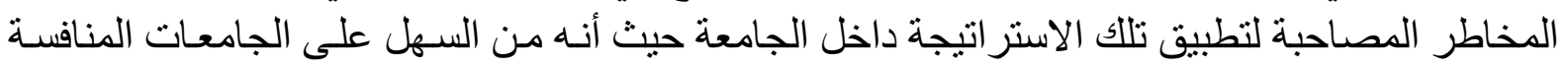

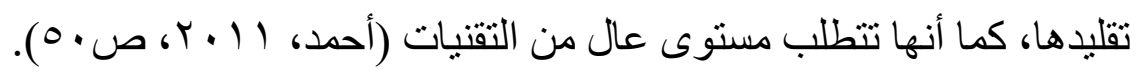
ب-استراتيجية التميز

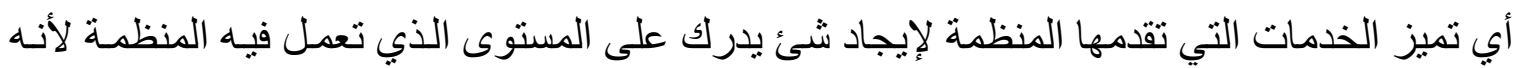

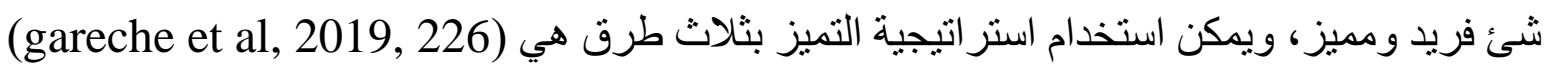

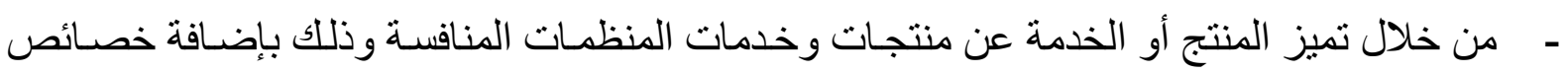
فريدة لها مما يعطيها جاذبية تنافسية.

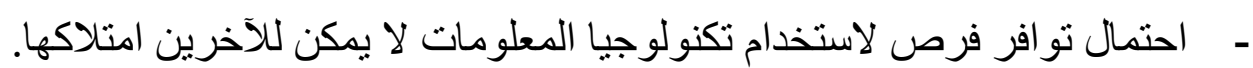

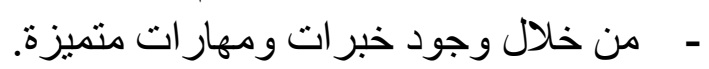

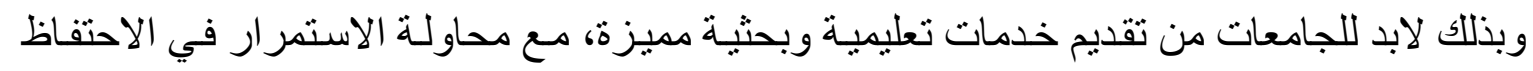

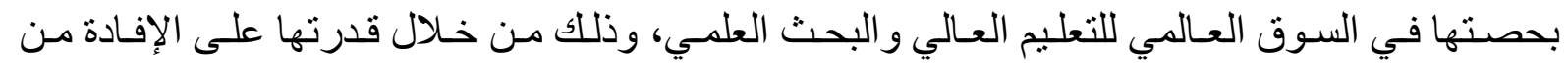

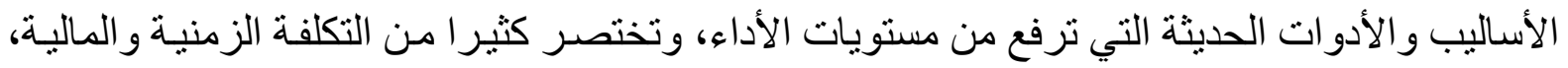

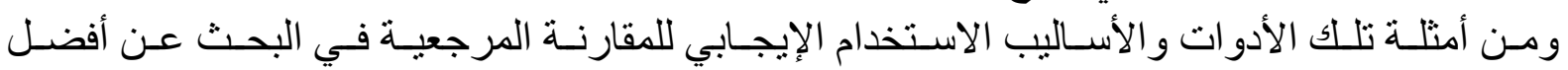

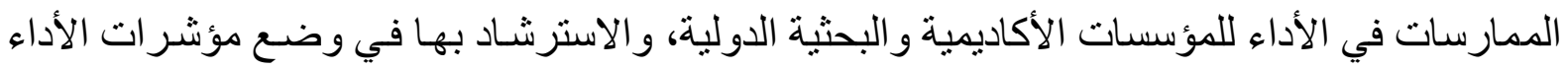

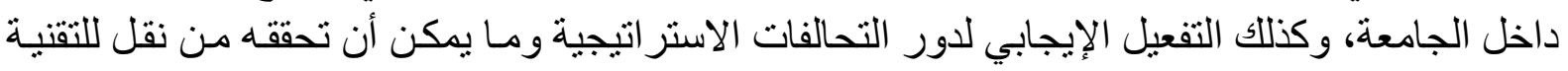




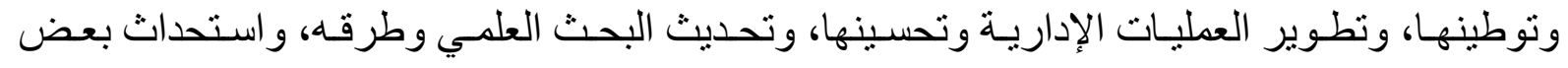

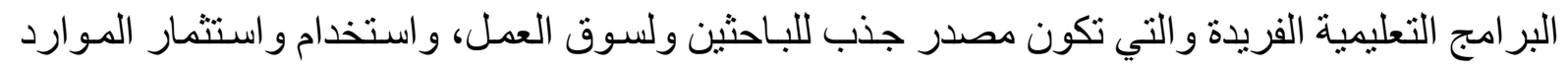

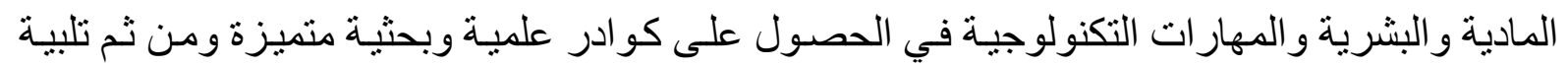
احتياجات الأسواق العالمية، وتحقيق منافع أكثر من الجامعات المنات المنافسة لها.

ج-استراتيجية التركيز

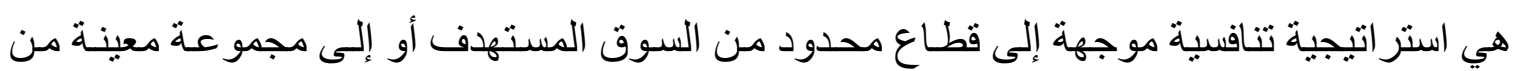

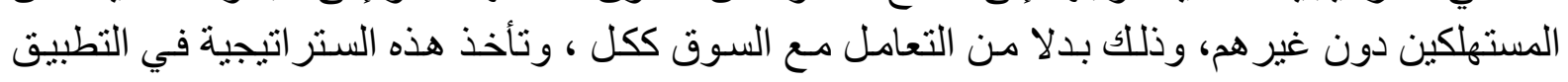
العملي شكلين هما (Ceglinski, 2016, p65): - التركيز مع خفض التكلفة: أي تحقيق ميزة تنافسية في قطاع معين من السوق تعتمد على خفض التكلفة. - التركيز على التمايز : أي تحقيق ميزة تنافسية في قطاع معين من السوق تعتمد على التمايز في المنتجات.

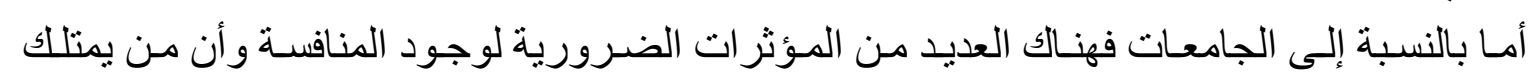

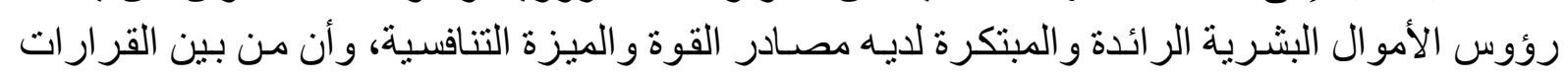

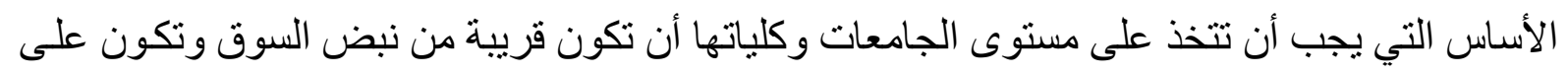

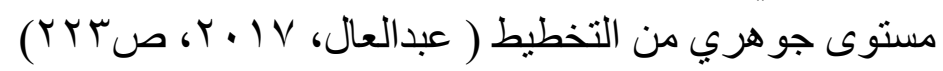

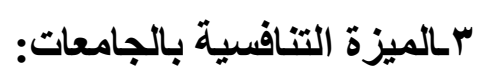

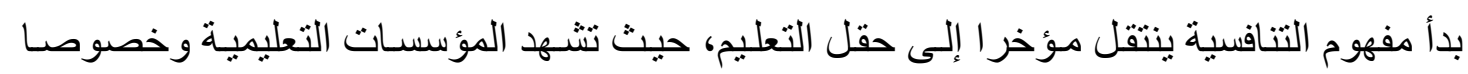

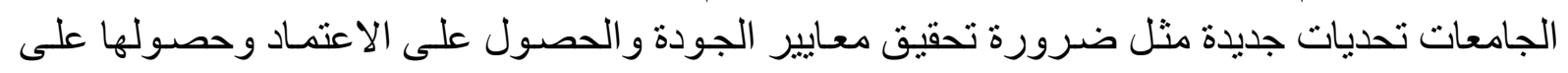

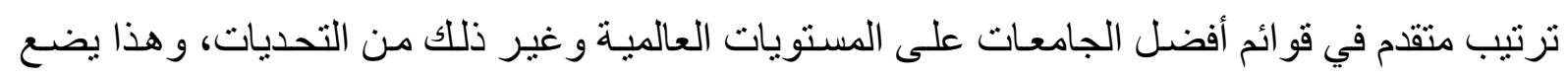

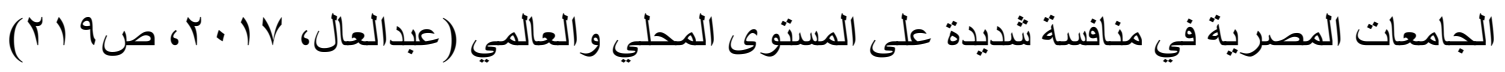

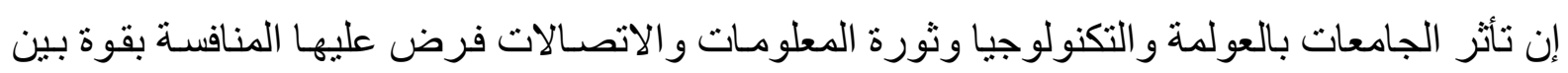

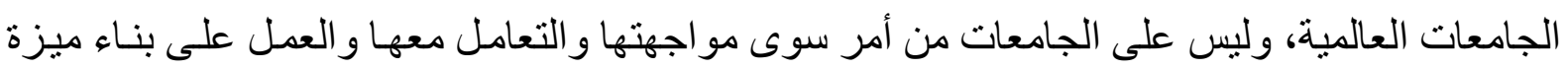

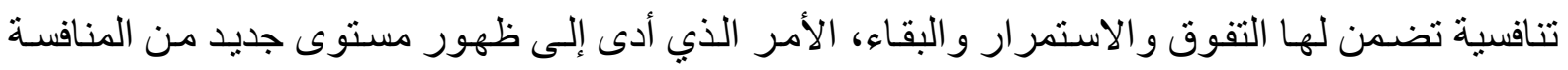

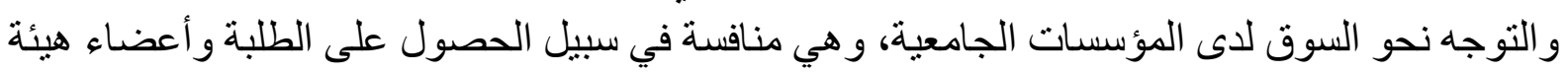

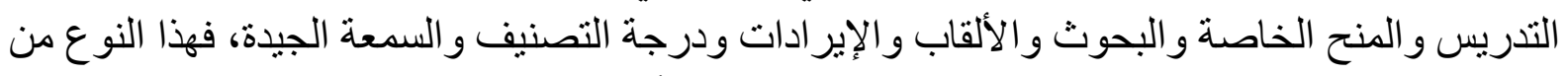

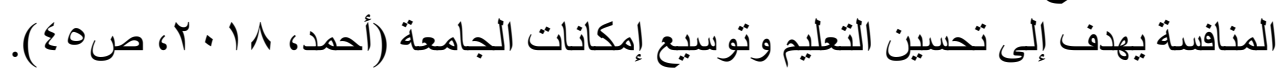

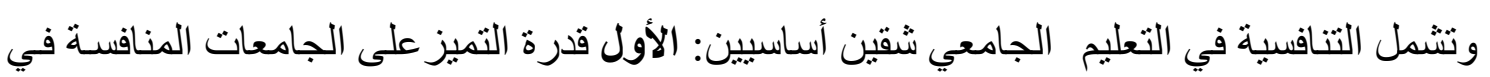

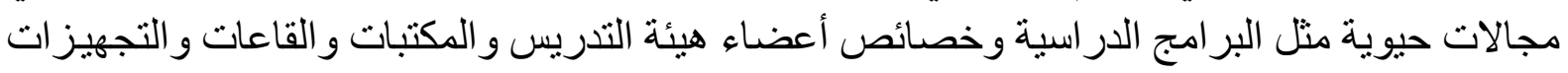

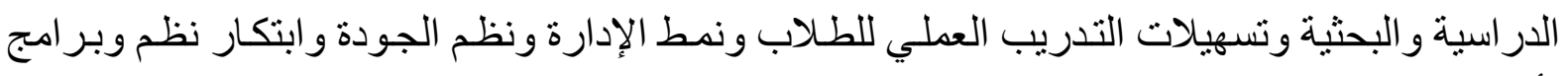

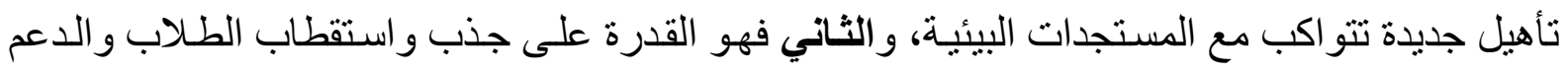

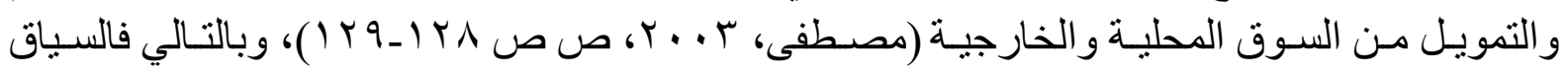

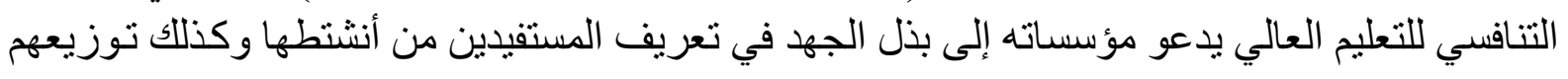




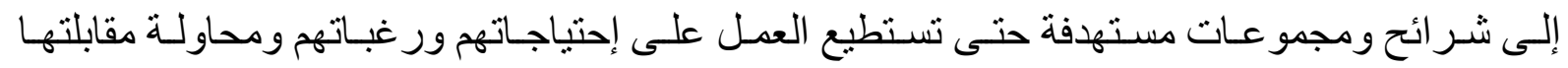

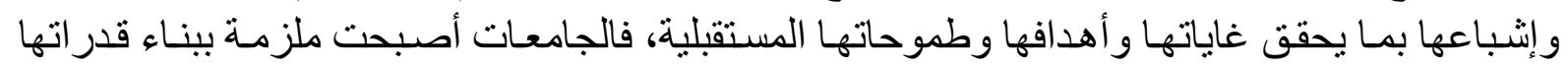

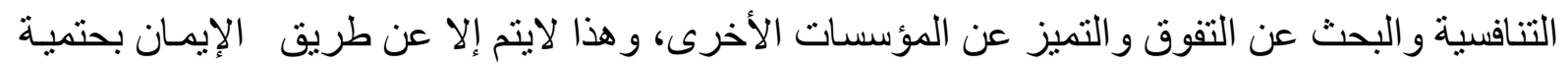

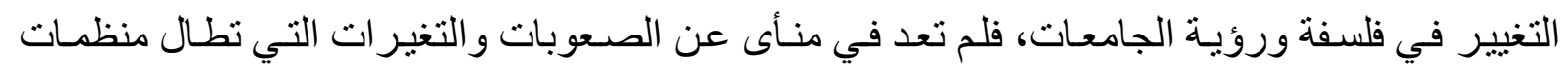

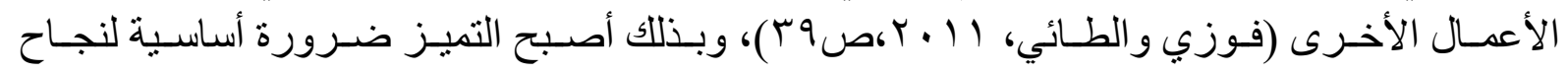

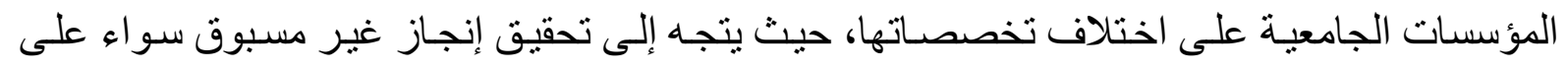

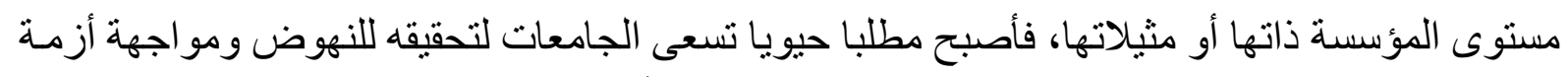

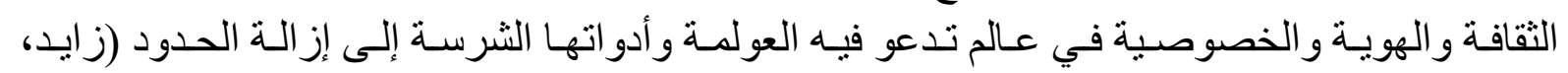
.(100. T. 11

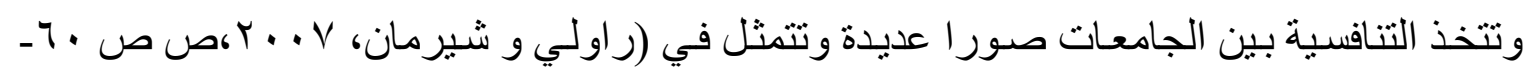

ح التنافس على الموارد: حيث تسعى كل جامعة إلى التنافس من أجل الحصول على الموارد و والأمو ال

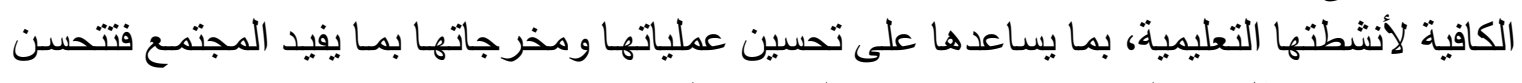

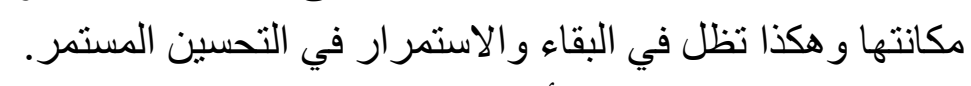

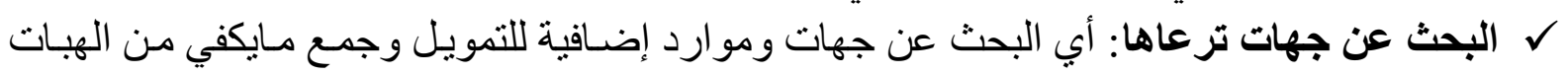
و المنح للجامعات. ل التنافس على الطلاب: حيث تر غب كل جامعة في جذب الكثير من الطلاب المتفوقين يضيفون المزيد

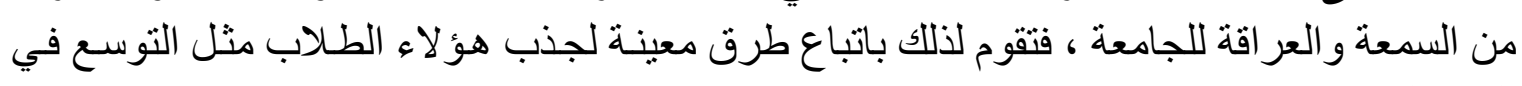
المنح الدر اسية و غير ها. ح التنافس على اجتذاب الهيئات التدريسية والإداريـة المتميزة و الاحتفاظ بها بمـا يدعم من قدرتها التنافسية ويعمل على تحسينها.

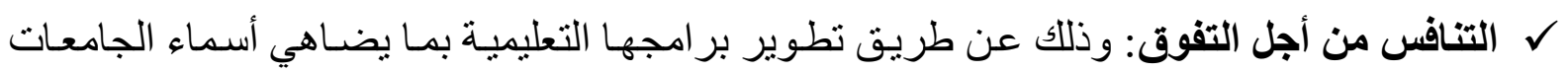

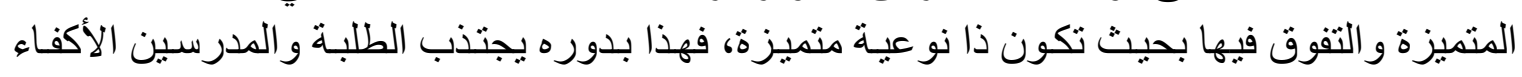

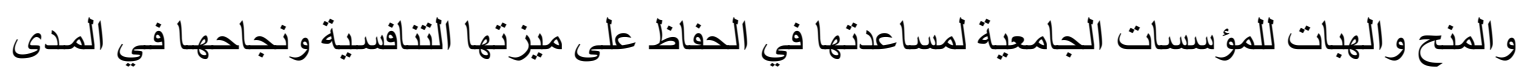

أـ أهداف الميزة التنافسية للجامعات:

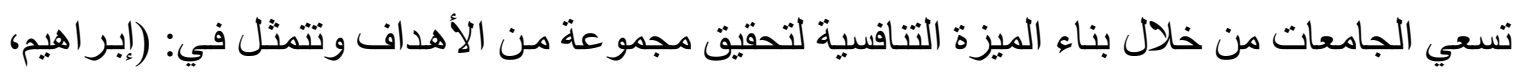

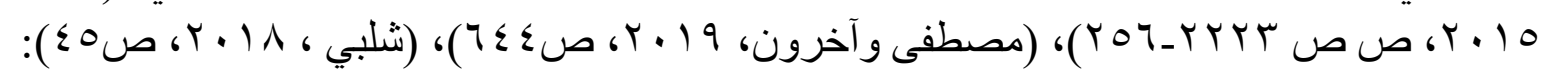

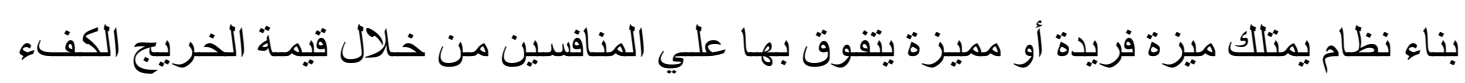

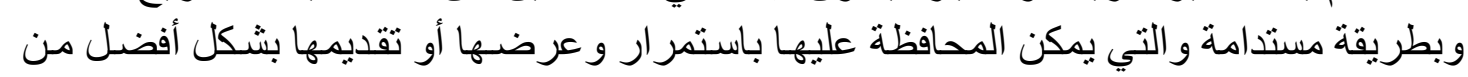
الآخرين .

ت تحسين المركز التنافسي للجامعة بين مثيلاتها.

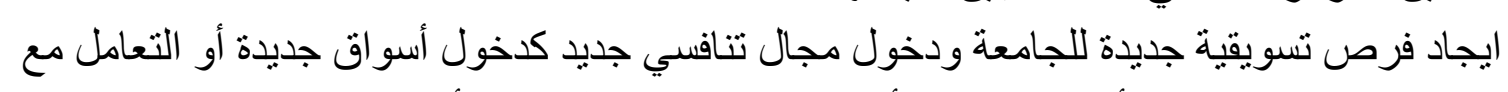

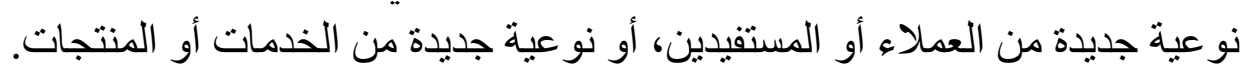




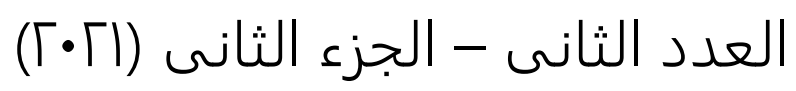
مجلة بحوث "العلوم التربوية "

ه تحديد المهار ات المطلوبة من مخرجات الجامعة وسوق العمل سواء أكان محليا أو إقليميا أو عالميا.

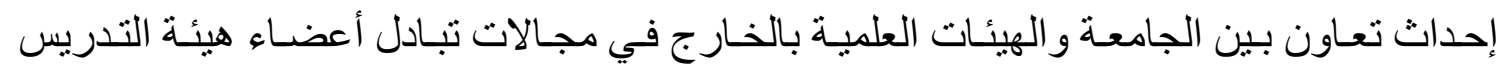

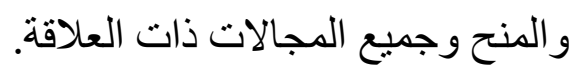

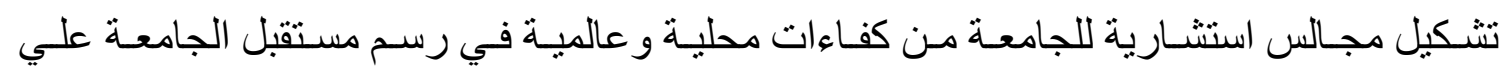
المستوي التنافسي العالمي. ه تشجيع نشر الأبحاث المتميزة في مجلات علمية التهية عالمية.

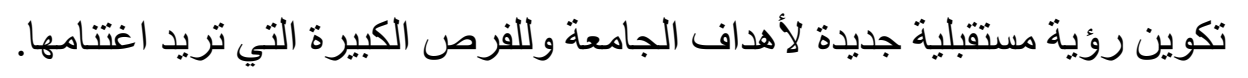
ب-أهمية الميزة التنافسية للجامعات:

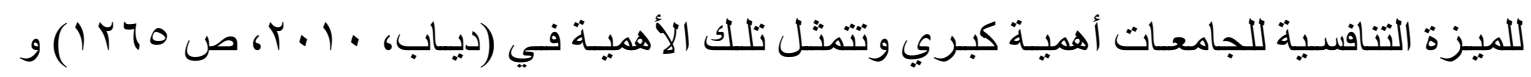

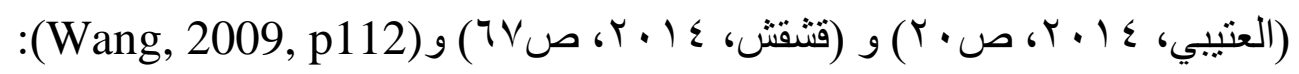

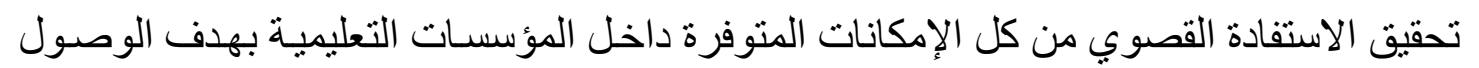

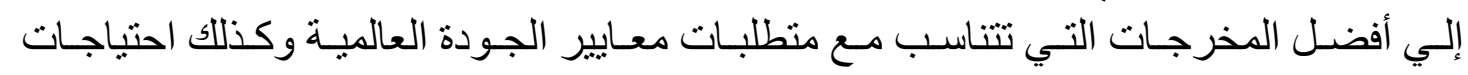

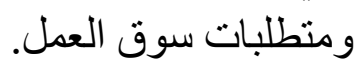

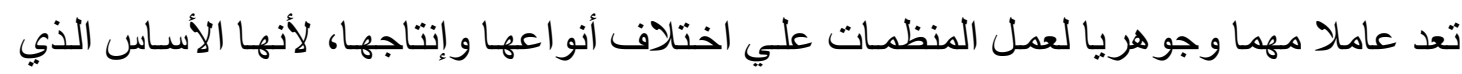

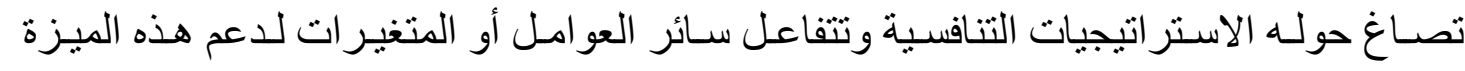
و انبثاق الاستر اتيجية الثناملة للمنظمة.

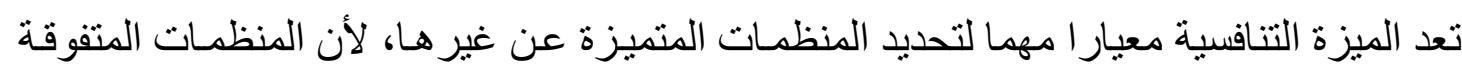

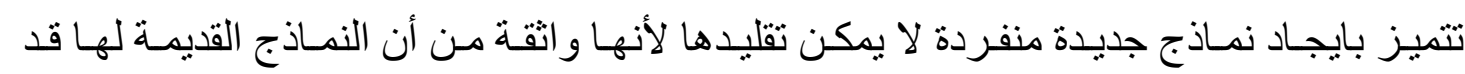

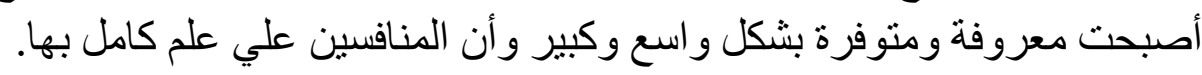

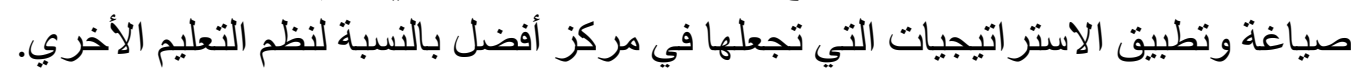

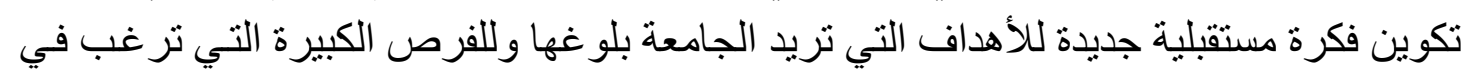
اغتنامها لكو نها مستندة علي موارد المنظمة وقدار اتها.

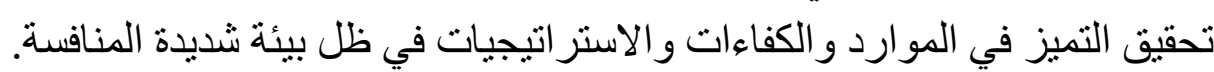

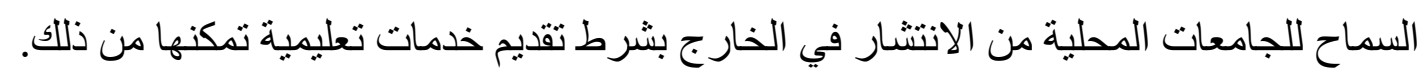

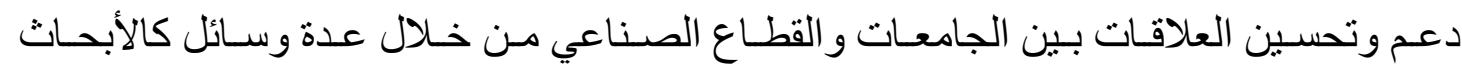

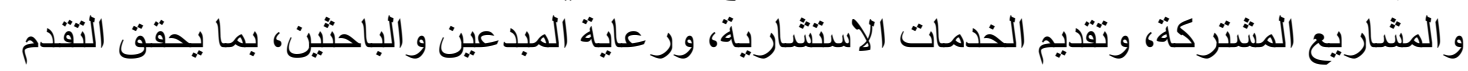

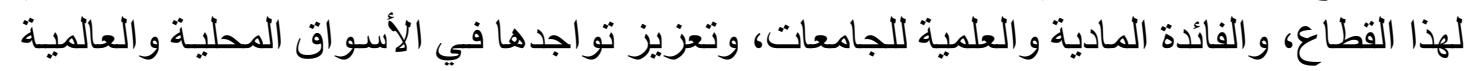
للتعليم الجامعي. ج-متطلبات تحقيق الميزة التنافسية في الجامعات :

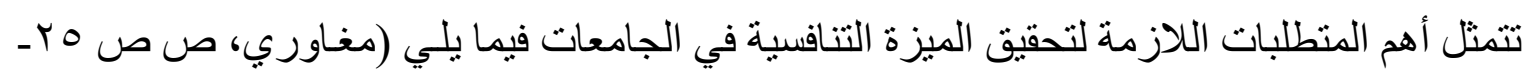

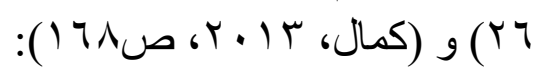




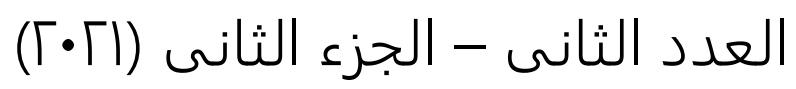
مجلة بحوث "العلوم التربوية "

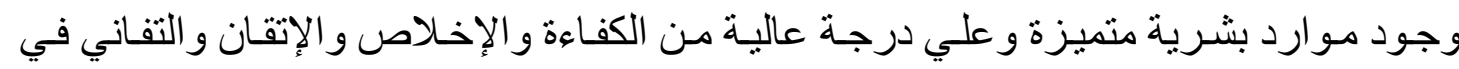

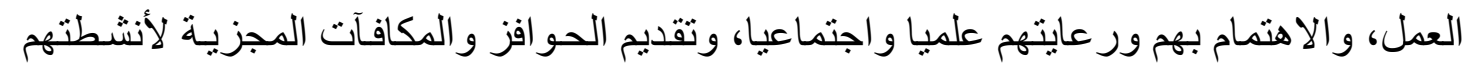

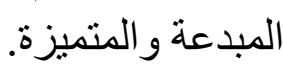
الأخذ بالمداخل الإدارية الحديثة.

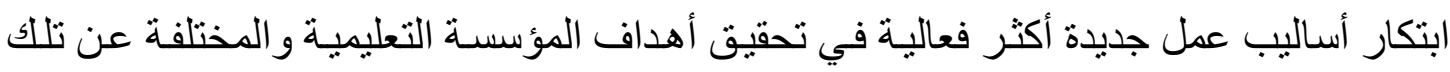

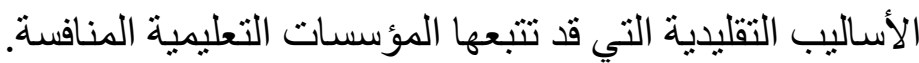

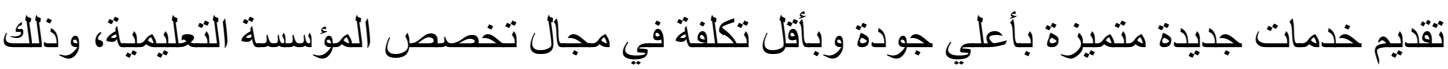

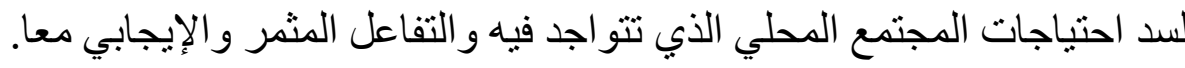

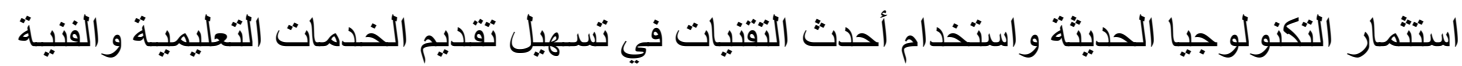
و الإدارية للطلاب و أعضاء هيئة التدريس و العاملين بالجامعة.

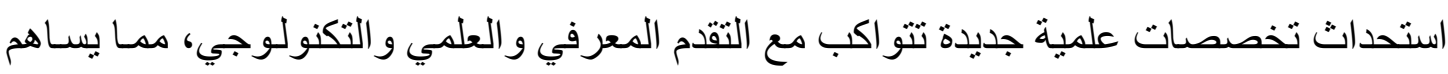

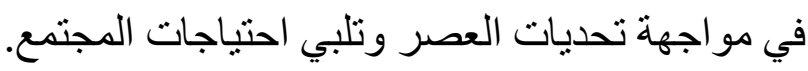

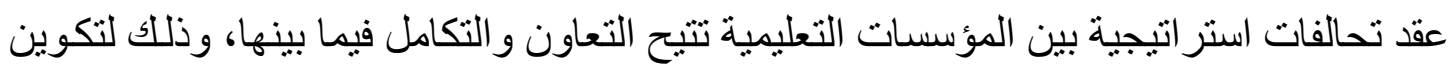
قوة تنافسية في بيئة العمل الخارجية. الإبداع سواء في الخدمات التعليمية أو الإدارية أو البحثية. المحور الثالث: دور الجامعات في تفعيل التشارك المعرفي لتحقيق الميزة التئة التنافسية

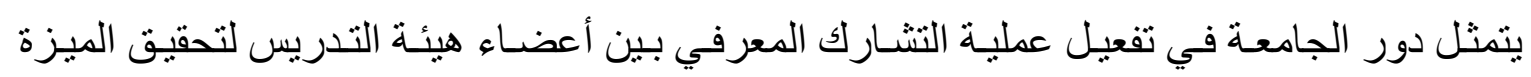

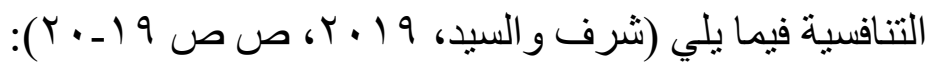
1- إعداد الكوادر الفنية المتخصصة.

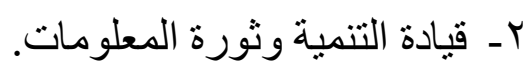

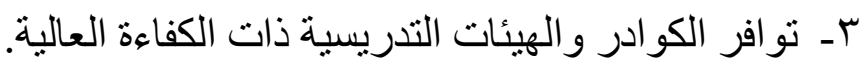

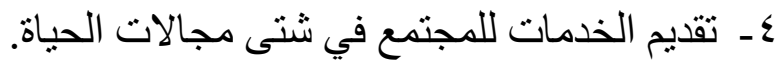

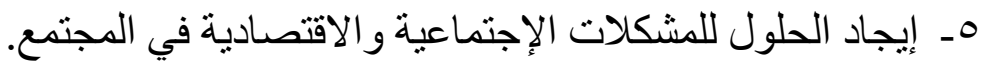
7- توجيه الطلاب نحو العلم و المعرفة و الأخلاق الحميدة.

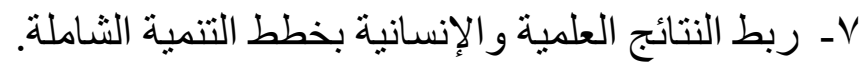
^ـ - توسيع فرص التعليم و التدريب.

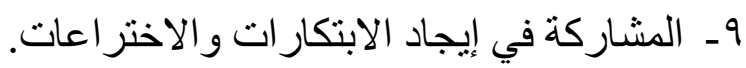

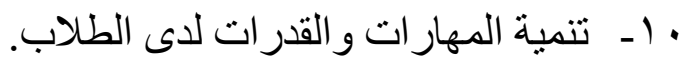

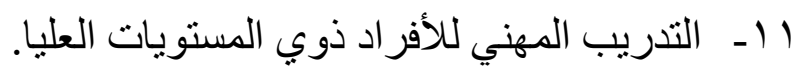
r ا ا - ـ اهتمام المجتمع ومؤسساته بالأساتذة و العلماء و والباحثين.

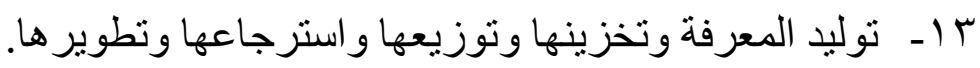

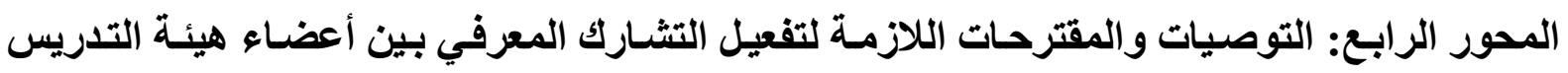
لتحقيق الميزة التنافسية بالجامعات المصرية: 
نظر الأهمية التشارك المعرفي بين أعضاء هيئة التدريس في تحقيق الميزة التنافسية بالجامعات

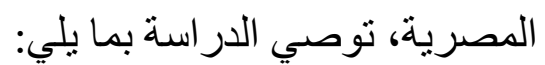

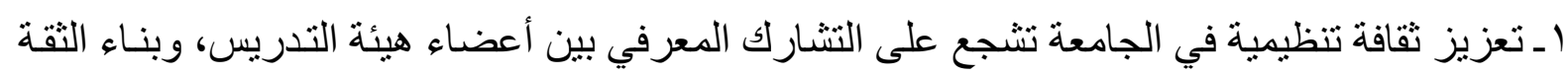
فيما بينهم، بهدف تحقيق التميز للجامعة ورفع تصنيفة تبفيا المحلي و العالمي. r ـ تشجيع أعضاء هيئة التدريس على الانفتاح على تجارب الآخرين فيما يخص عملية التشارك المعرفي.

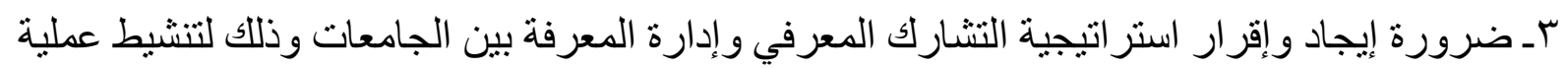
نقل المعرفة وتداولها داخل الجامعات.

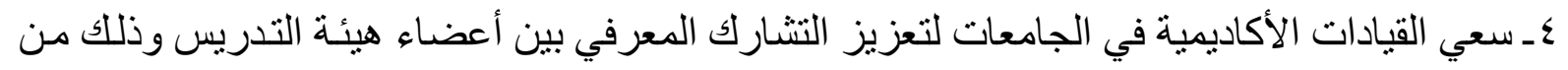

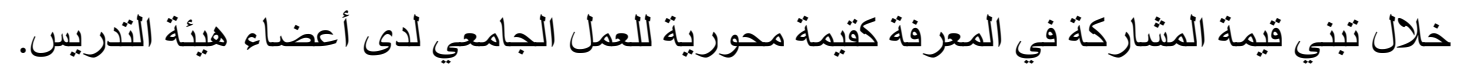

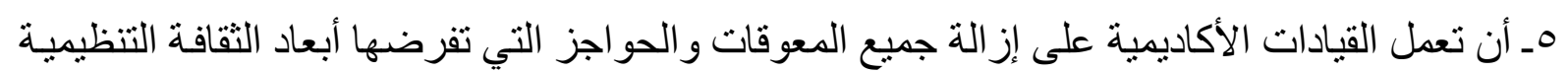

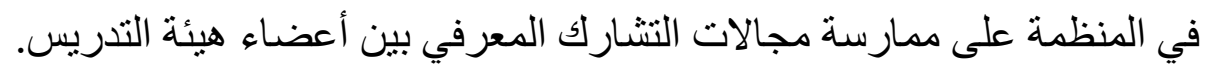

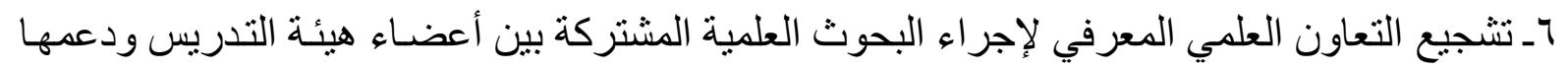

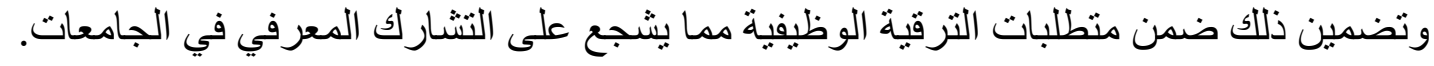

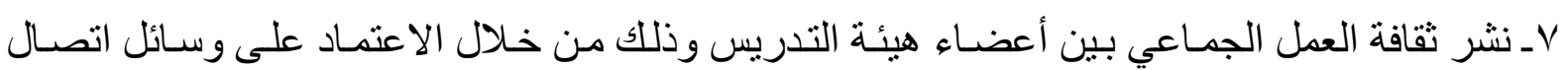

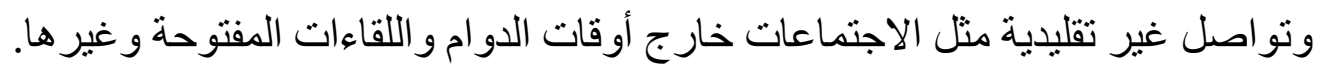

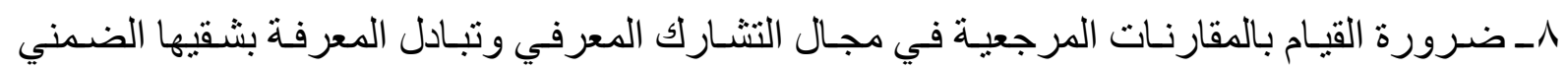

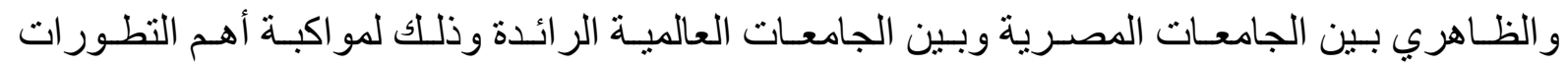

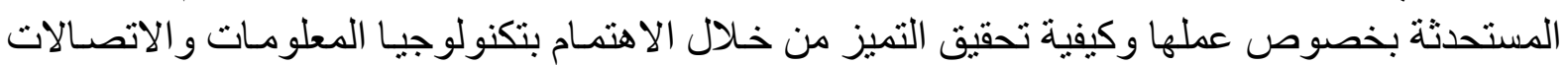

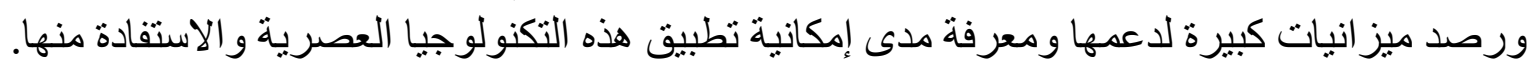

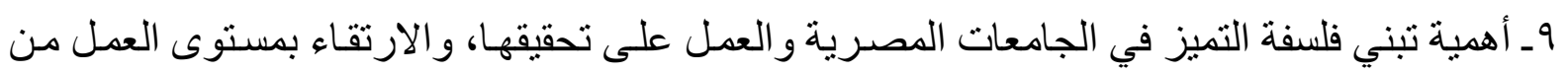

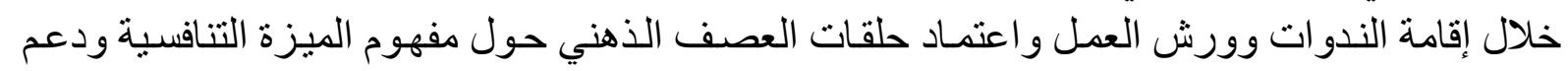

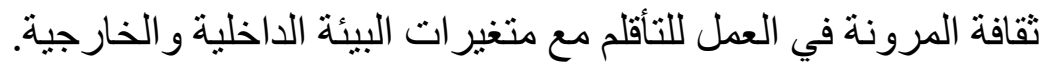

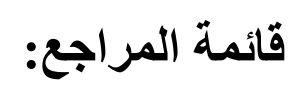

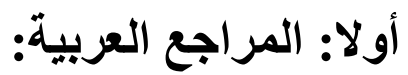

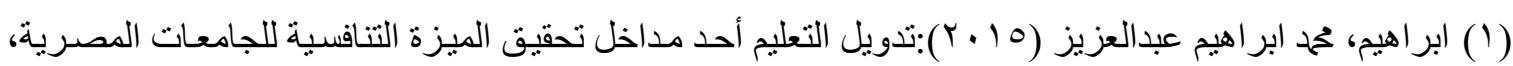

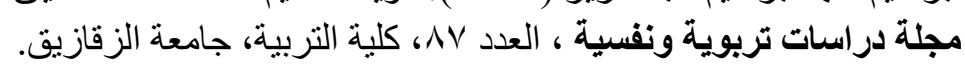

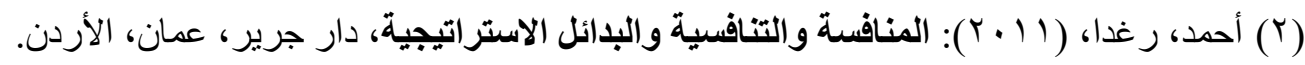

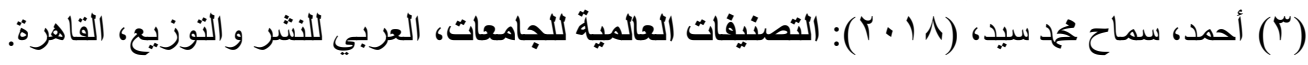

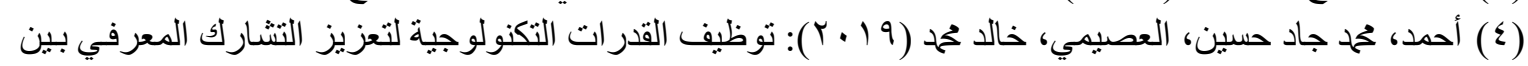

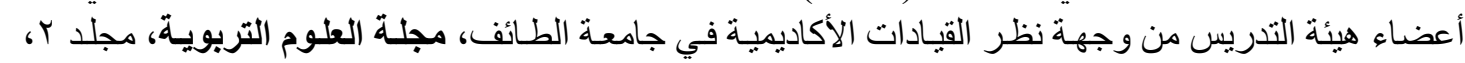
العدد ع، كلية التربية بالغر دقة، جامعة جنوب الو ادي. 


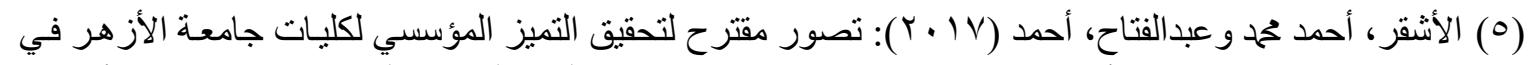

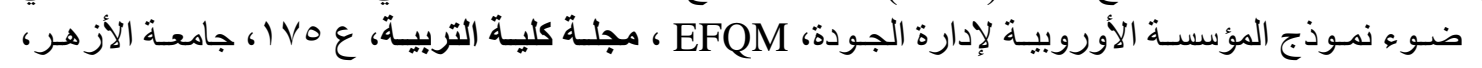
أكتوبر.

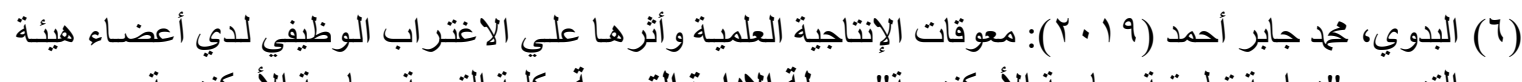

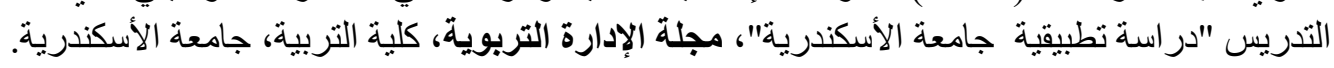

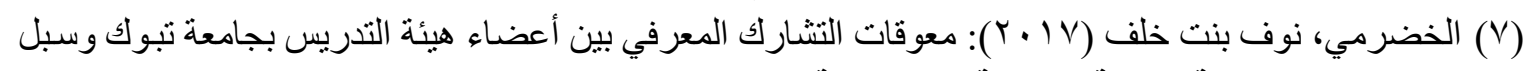

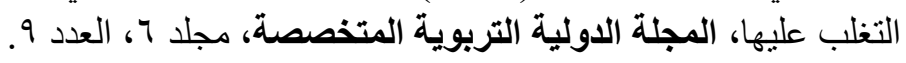

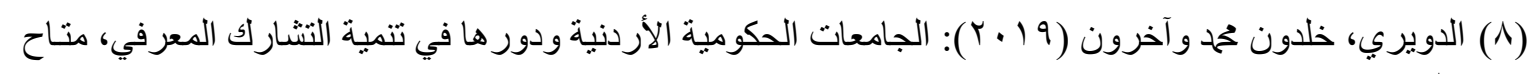

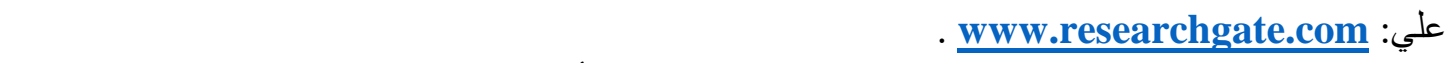

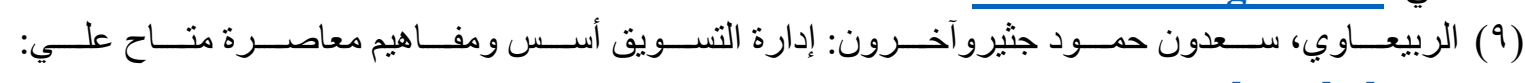
.wWw.almanhal.com

السلمي، علي (Y9al (19): الإدارة المصرية مواجهة الواقع الجديد، دار غريب، القاهرة.

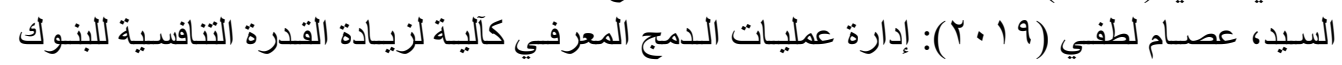

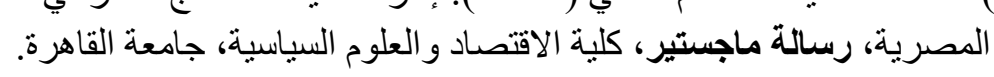

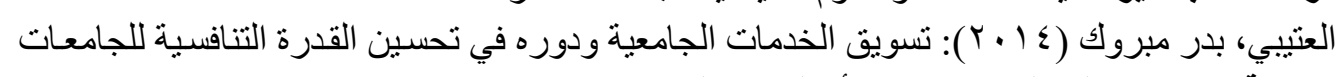

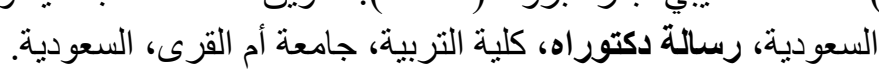

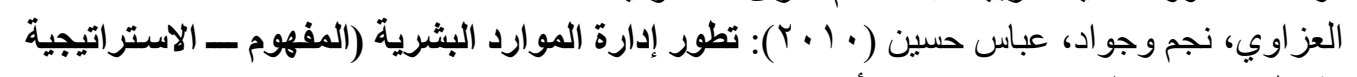

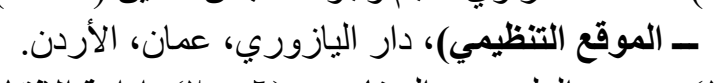

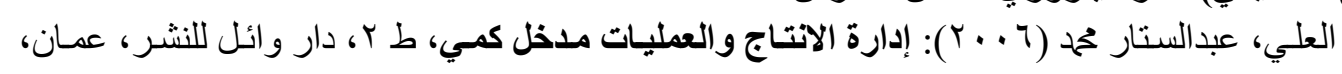
الأردن.

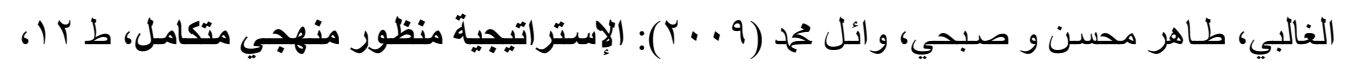
دار وائل، عمان، الأردن.

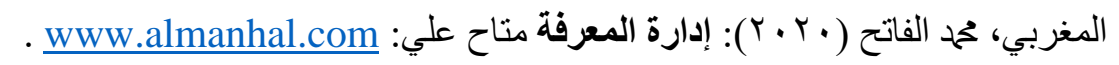

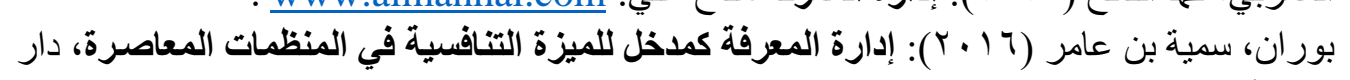

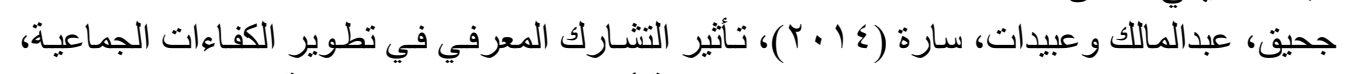

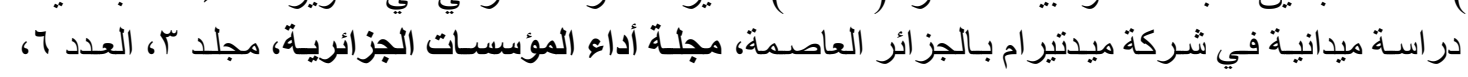

حافظ، عبدالناصر علك و عباس، حسين وليد (9 . ب): الأنماط القيادية الطريق لبناء الميزة التنافسية الجزائر.

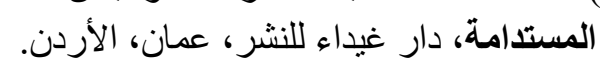

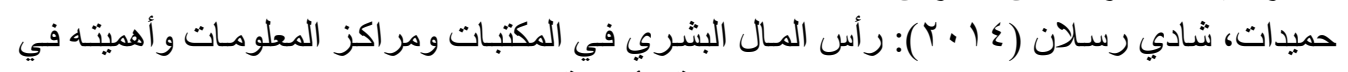

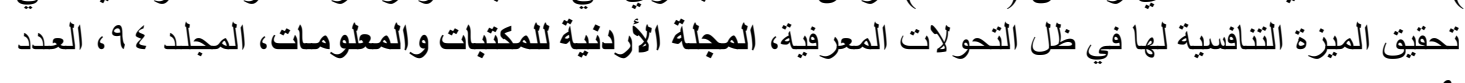

خليل، نبيل مرسي (991 (1)): الميزة التنافسية في مجال الأعمال، مركز الأسكندرية، مصر.

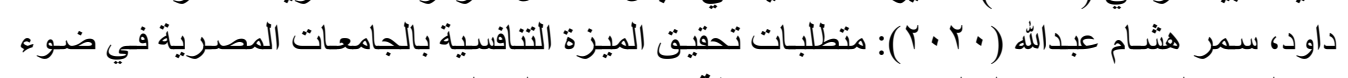
9

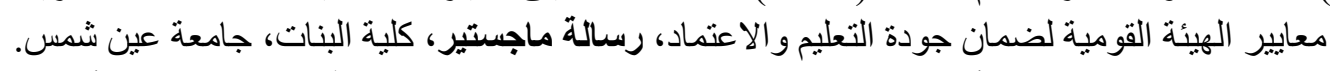

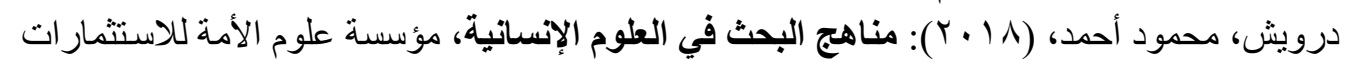

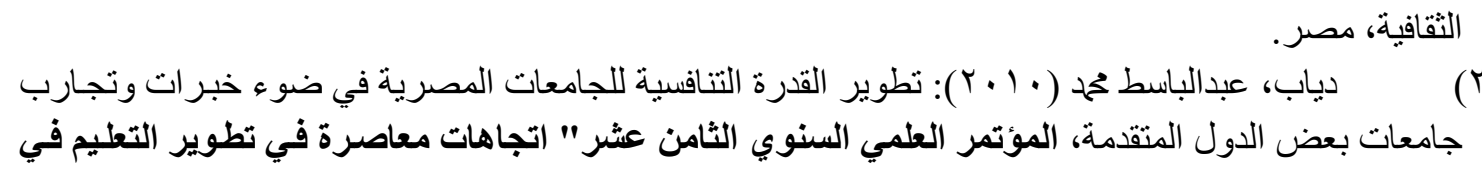

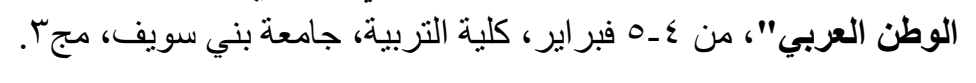
- 9 . - 


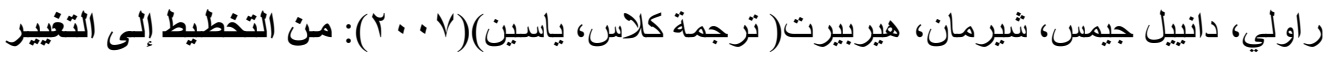

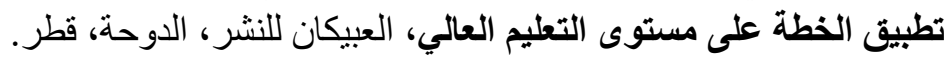

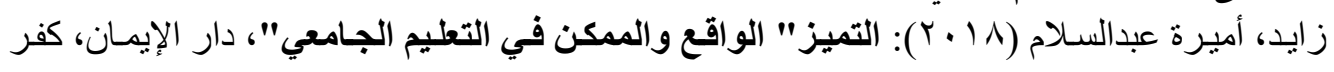

الثيخ، مصر.

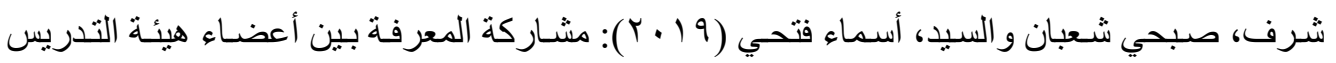

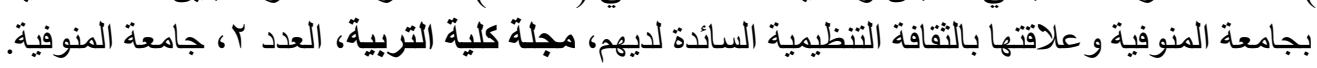

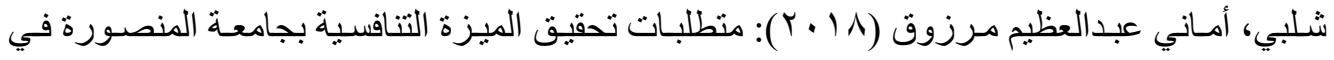

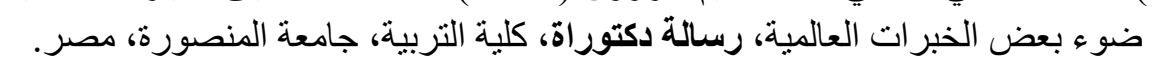

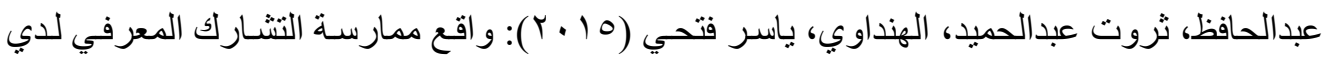

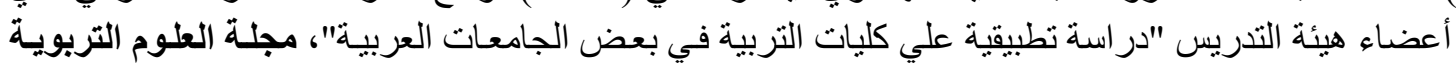

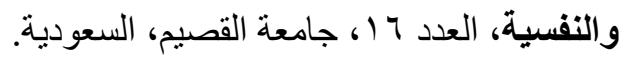

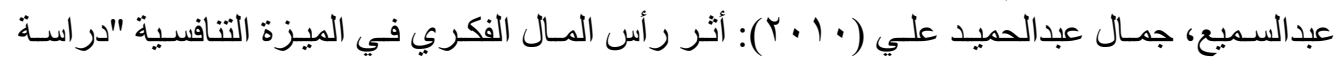

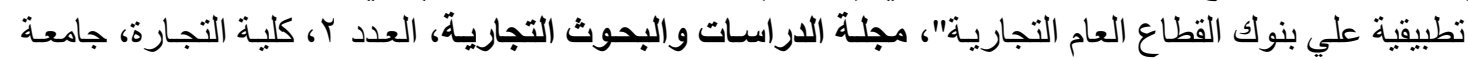

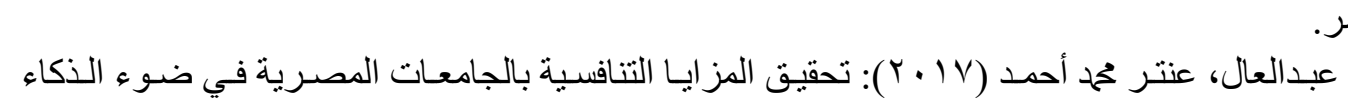

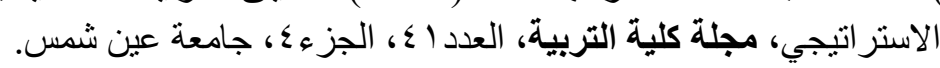

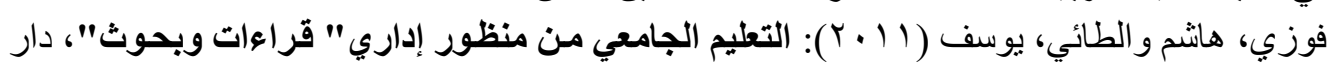
اليازوري، عمان، الأردن.

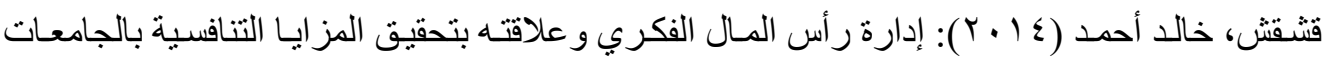

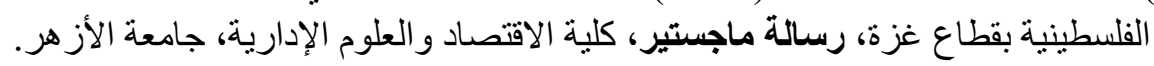

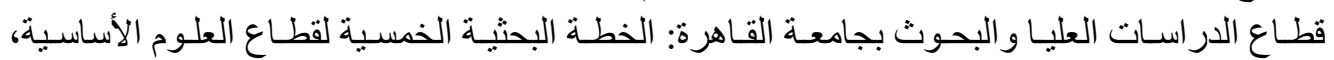

. WWW.cu.edu.eg متاح

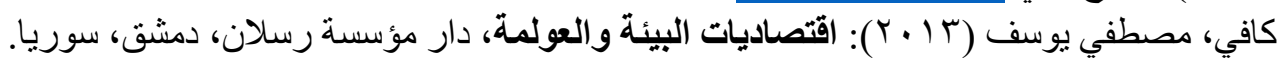

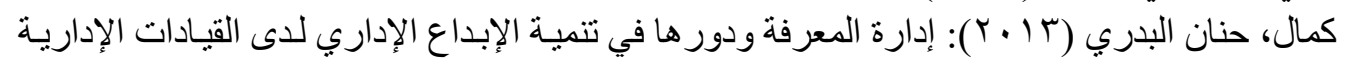

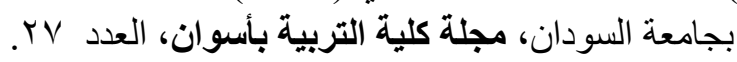

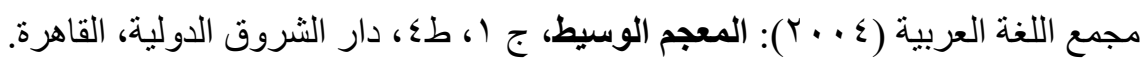

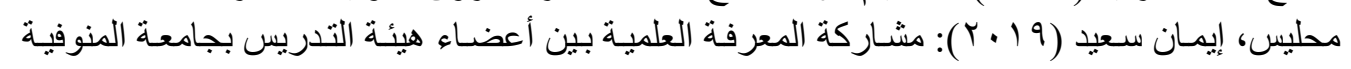

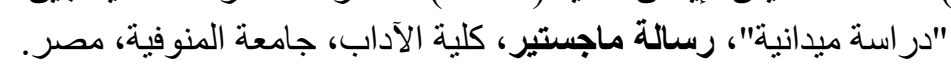

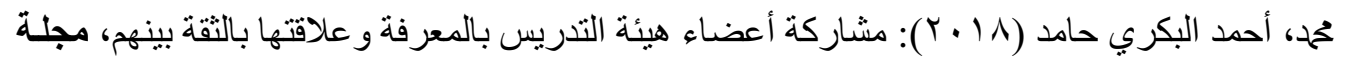

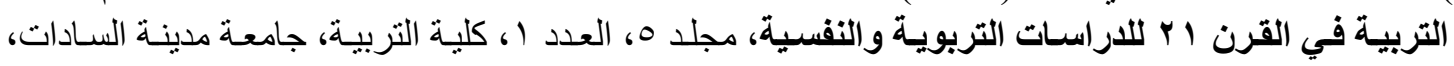

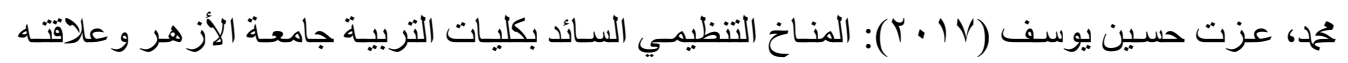

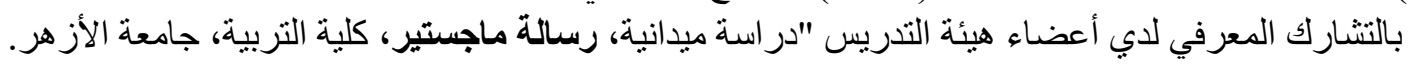

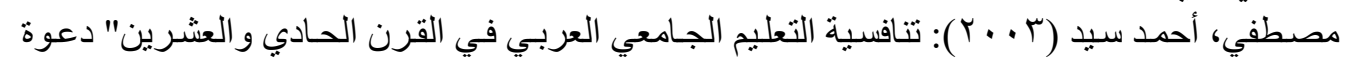

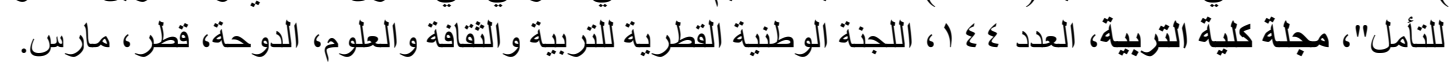

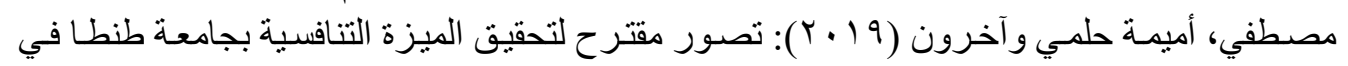

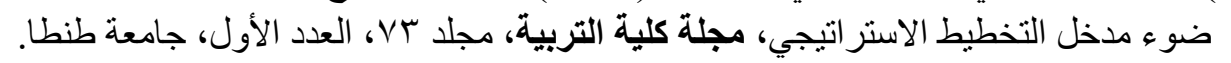

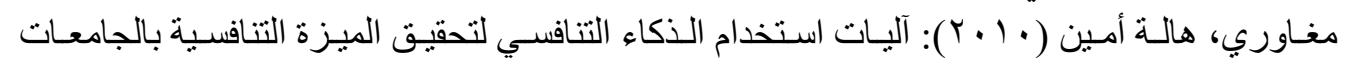

المصرية ، مناح على

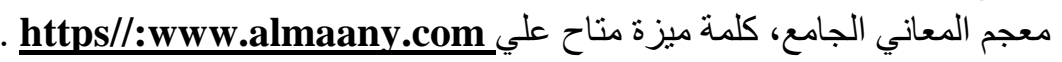

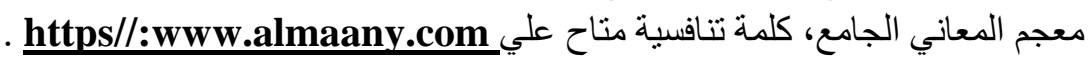


وزارة التعليم العالي و البحث العلمي (9 ( ب ب): الاستراتيجية القومية للعلوم والتكنولوجيـا والابتكار،

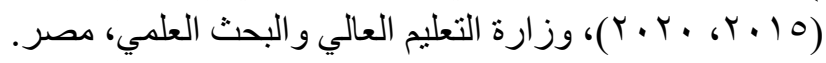

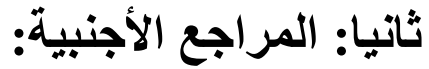

1- Jain,k , et al (2007): Knowledge Sharing among Academic Stuff : Acase Study Of Business Schools In Klang Valley ,Malaysia ,Journal For The Advancement Of Science and Arts,no.(2), pp.23-29

2- Dee, Jay \& Leisyte, Liudvika(2017): Knowledge Sharing and Organizational Change In Higher Education, Journal Of Learning Organization, Vol.(24), N.(5), pp.355-365

3- Shaqrah, A, et al (2011): Affecting Factors of Knowledge Sharing on CRM: An Empirical Investigation Using Structural Equation Modeling World, Journal Of Social Science, Vol. (1), No .(1), P.54

4-Ozbek \&Toplu (2011): Empowered Employees, Knowledge Sharing, International of Business and Management Studies, Vol .(3) , No.(2), P.23.

5-Gurteen, D (1999): Creating a Knowledge Sharing Culture, Knowledge Management Magazine, Vol.(5), No.(5), PP.1-3

6-Bulan, Semlinda, \& Sensuse, Dana Indra (2018): Knowledge Sharing Model Among Academics Staff in Universities, Journal of Information Systems, Vol .(8), PP. 133-139

7- Akbar, Ali, et al (2012): Determinants of Knowledge Sharing Behavior, International Conference, Business and Marketing Management, Vol. (29),P.209

8- Ugochi, Nwakego, et al (2013): Knowledge Sharing Behavior of Postgraduate Students in University of Malaya, The Electronic Library, Vol.(31), No.(6), P.720

9-Bo-chang (2018): Active Knowledge Sharing in Online Group Work, New Horizons in Adult Education \& Human Resource Development Journal, Vol.(30), No.(3), PP .41-59

10-Tosh, Sujata San \& Panda, Santosh (2016): Sharing of Knowledge Among Faculty in Mega Open University, Open Praxis Journal, Vol.( 8), N.(3), PP.247-264

11-Wanger, Beverly (2003): Learning and Knowledge Transfer in Partnering, Journal of Knowledge Management, $\mathrm{Vol}$ (7), No( 2), PP.97-113

12- Zheng, Tingting (2018): a literature Review on Knowledge Sharing, Open Journal of Social Science, No.(5), PP.51-58

13- Yang, J.T (2007):” Knowledge Sharing : Investigating Appropriate Leadership Roles and Collaborative Culture", Tourism Management, Vol.( 28), No.( 2 ), P.78.

14-Ching, M, et al (2008): Knowledge Sharing in Academic Institution, Study of Multimedia University, Electronic Journal of Knowledge Management, Vol .(7), PP. 313- 324.

15-Lin, Hsiu-Fen (2007): Knowledge Sharing and Firm Innovation Capability: an Empirical Study, International Journal of Manpower, Vol.(28), No.(3). 


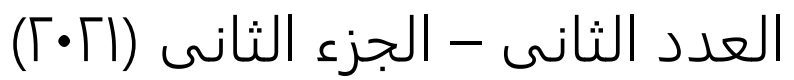

مجلة بحوث

16- Eidizadeh, Rosa, et al (2017): Analaysing The Role Of Business Intelligence, Knowledge Sharing and Organizational Innovation On Gaining Competitive Advantage, Journal of Work Place Learning, vol.29, no.4, pp.250- 267

17- Peng, He (2011): Why and When Do People Hide Knowledge?, Journal of Knowledge Management, Vol.(17), No.(3), PP.398-415

18- Sadalia, Isfenti, et al (2020): Entrepreneurial Orientation And Innovation To Competitive Advantage Of SMES In North Sumatera Mediated With Business Financing Factor, Journal Of Critical Reviews, India, Vol.(7), Issue.(1), PP. 236-240

19- Gareche, Manijeh ,et al (2019): A Comprehensive Literature Review In Competitive Advantages Of business, International Journal Of Advanced Studies In Humanities And Social Science, Iran, Vol.(8), Issue. (3), PP.223-240

20- Ceglinski, Pawel (2016): The Concept Of Competitive Advantages Logic, Sources And Durability, Journal Of Positive Management, Poland, Vol.(7), No.(3), PP. 57-70

21- Wang, c. et al (2009): "Knowledge Management Orientation, Market Orientation, And Firm Performance: An Integration And Empirical", Journal Of Strategic Marketing, United Kingdom, Vol.( 17), N.(2), PP.103-130.

22-Saravanan, N \& et al (2017): Knowledge Sharing and Barriers in Organization: a Conceptual Paper on Knowledge - Management Strategy, Indian Pacific Journal of Accounting and Finance, Vol.(1), N.(4), PP.32-41.

23-Rusuli, M \& Tasmin, R (2010): Knowledge Sharing Practice in Organization, International Conference on Ethics and Professionalism, Malaysia, PP.796-803.

24-Paloti, R (2010): Knowledge Sharing, Conference Paper in MANLIBNET, Kozokode (India), Available at: https://core.ac.uk/download/pdf/11887355

25-Koivisto, E (2018): Knowledge Management and Sharing on Internal Best Practices in The Global Service Business, Master Thesis, LUT School of Business and Management, Lappeenranta University of Technology, Helsinki, Finland.

26-Ismail, M \& Yusof, Z (2010): The Impact of Individual Factors on Knowledge Sharing Quality, Journal of Organizational Knowledge Management, N.(1), PP.1-12, Available at: https://ibimapublishing.com/articles/JOKM/2010/327569/

27-Oye, N, Mazleena, S, \& Noorminshah,A (2011): Knowledge Sharing in Work Place: Motivators and Demotivators, International Journal of Managing Information Technology, Vol.(3), N.(4), PP.71-84.

28-Haan, Haijing Helen(2015): Competitive Advantage, What Does it Really Mean in The Context of Public Higher Education Institutions?, International Journal of Educational Management, Vol.( 29), N.(1), PP.45-56. 


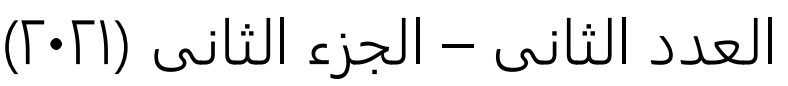

\title{
"Activating Knowledge Sharing among Academic stuff to Achieve Competitive Advantage in Egyptian Universities"
} $\underline{B y}$ Enas Abdallah Ahmed Abdelaal

(Master)Degree -Department of educational -

Faculty of women -Ain-shams University

Enas.ahmed@women.asu.edu.eg Supervision

Prof. Suzan Mohamed Elmahdy

Professor of pedagogy - faculty of women- Ain-shams University

Suzan-elmahdy@hotmail.com

Prof.Dr.Hala Amin Maghawry

Assistant Professor of pedagogy - Faculty of women - Ain-shams University

\section{halamaghawry@hotmail.com}

\begin{abstract}
The current research aimed at defining the conceptual framework for knowledge sharing in universities in terms of presenting the concept of knowledge sharing, its objectives and its importance, and identifying the most important means and methods of achieving it within universities and the requirements for achieving it, up to the most important obstacles that limit the process of knowledge sharing among faculty members, then moving to the theoretical foundations of advantage. Competitiveness by presenting its concept and strategies for achieving it, and the objectives of the competitive advantage of universities and its importance and requirements for achieving it within universities, then identifying the role of universities in activating the process of knowledge sharing among faculty members to achieve competitive advantage, and the research reached a set of recommendations and procedural proposals to activate knowledge sharing between members of the faculty Teaching to achieve competitive advantage in universities is one of the most important of which is building an organizational culture within universities that encourages faculty members to share knowledge and build trust between them, with the aim of achieving excellence for universities and raising their local and global rankings, and the need to adopt the philosophy of excellence in Egyptian universities and work to achieve it, and to raise the level of work from During the holding of seminars and workshops and the adoption of brainstorming sessions $\mathrm{h}$ The concept of competitive advantage and support for a culture of flexibility at work to adapt to the variables of the internal and external environment, and the research used the descriptive approach to suit the nature of the research.
\end{abstract}

Key words:knowledge sharing - Competitive Advantage- Egyptian Universities 